\title{
Cross-subsidization in employer-based health insurance and the effects of tax subsidy reform
}

\author{
Svetlana Pashchenko* \\ Uppsala University
}

\author{
Ponpoje Porapakkarm ${ }^{\dagger}$ \\ University of Macau
}

February 15, 2013

\begin{abstract}
A major source of insurance coverage for non-elderly adults in the US is employer-based health insurance market. Every participant of this market gets a tax subsidy since premiums are excluded from taxable income. However, people have different incentives to participate in the employer-based pool: since premiums are independent of the individual risk, high-risk individuals receive implicit cross-subsidies from low-risk individuals. In this paper we explore several ways to reform the tax subsidy by taking this implicit cross-subsidization into account. We construct a general equilibrium heterogeneous agents model and calibrate it using Medical Expenditure Panel Survey Dataset. We find that even though the complete elimination of the tax subsidy leads to the unraveling of the employer-based pool there is a room for substantial savings by targeting the tax subsidy. More specifically, the same level of risk-sharing in the employer-based market can be achieved at only one third of the current costs if i) the tax subsidy is targeted only towards low-risk people who have weak incentives to participate in the pool, and ii) employer-based insurance premiums become age-adjusted. To improve welfare outcome of this reform the tax subsidy should also be extended to low-income individuals.
\end{abstract}

Keywords: health insurance, tax subsidies, risk sharing, general equilibrium JEL Classification Codes: D52, D91, E21, E65, I10

\footnotetext{
*Email: sap9v@virginia.edu

†Email: ponpojep@umac.mo
} 


\section{Introduction}

Most of the non-elderly adults in the US $(63 \%)$ purchase health insurance in the employer-based market. An important feature of this market is community rating, i.e. the insurance premiums are independent of health and age of individuals. In order for the community-rated market to provide good risk-sharing there should be enough healthy people willing to participate. In the employer-based market an important incentive to participate is provided by tax subsidies: the employer-based premiums are excluded from federal and state taxes. In 2009 the costs of this subsidy were equal to $\$ 260$ billion, making it the largest of the tax expenditures by the federal government and the third largest expenditure on health care, after Medicare (\$400 Billion) and Medicaid ( $\$ 300$ Billion). ${ }^{1}$

In this paper we ask whether it is possible to reduce the spending on the tax subsidy without destroying the employer-based pool? Our question is motivated by the observation that every participant in the employer-based market gets a tax subsidy but people have different incentives to participate in this pool. The employer-based pool involves a sizeable cross-subsidization from people with low expected medical costs (young and healthy) to people with high expected medical costs (old and unhealthy). The former pay more and the latter pay less for their health insurance than they would pay if insurance premiums are adjusted for individual risk. Thus, people with high expected medical costs have stronger incentives to join the pool than people with low expected medical costs. Based on this intuition we explore several ways to better target the tax subsidy and evaluate the effects of these alternative subsidy schemes on tax expenditures and risk-pooling in the employer-based market.

Our approach is based on a quantitative heterogeneous agents model augmented with medical spending shocks. In the model, people can buy insurance against these shocks in the individual or employer-based markets. An important difference between these two markets is that in the former the premiums are risk-adjusted while in the latter there is community-rating, meaning that healthy and unhealthy people face the same premium. People are heterogeneous in their expected medical costs which creates different incentives to participate in the community-rated market: people with low expected costs may prefer to buy risk-adjusted insurance (or self-insure) while people with high expected costs prefer to participate in the community-rated pool. We also model the differential treatment of health insurance embedded in the tax code: employer-based premiums are excluded from taxable income while individual market premiums are not. We calibrate the model using Medical Expenditure Panel Survey (MEPS) dataset by reproducing the empirical life-cycle patterns of employment and insurance coverage as well as the key aggregate

\footnotetext{
${ }^{1}$ Gruber, (2011).
} 
statistics in the U.S.

Our findings are as follows. First, we show that if the tax exclusion is substituted by a flexible direct subsidy that is targeted only at people with weak incentives to participate in the employer-based pool, the costs of subsidizing people with employer-based insurance can be decreased by $74 \%$ without any damage to the risk-sharing. To achieve this outcome the amount of the direct subsidy should depend on the difference between the employer-based premium and the risk-adjusted premium of each individual. Even higher costs savings can be achieved if premiums in the group market become age-adjusted, i.e. premiums can vary with age (but not with health). Because medical costs increase quickly with age, community-rating involves a sizeable cross-subsidization from the young to the old. Thus, the young need large direct subsidies in order to be willing to participate in this pool. Allowing the premiums to be age-adjusted reduces the size of cross-subsidization inside the pool thus decreasing the size of the direct subsidy needed to hold the pool together.

Second, using the results from the direct subsidy scheme we explore how to reform the existing tax exclusion in order to obtain a similar outcome. We find that the reform that maintains good risk-sharing in the employer-based pool while significantly reducing the tax expenditures consists of two steps: i) allowing the premiums in the employer-based market to be age-adjusted, and ii) giving the tax subsidy only to those participants of the employer-based pool who have low current medical spending. ${ }^{2}$ Under this reform the spending on the tax subsidy constitutes only a third (34.6\%) of the amount in the baseline economy and the tax rate decreases by one percentage point, while the take-up rate of the employer-based insurance slightly increases (97.1\% comparing to $94.2 \%$ in the baseline). In contrast, if the tax subsidy is completely eliminated the take-up rate goes down to $6.3 \%$. We repeat the analysis for the economy after the health reform described in the Affordable Care Act (ACA) is implemented and find that the proposed tax subsidy reform achieves a similar outcome.

Finally, our welfare analysis shows that our proposed tax subsidy reform achieves much higher welfare gains if low-income people (with income below $200 \%$ of the Federal Poverty Line) are also allowed to keep the tax subsidy. This is because best risk-pooling is achieved when tax subsidies are targeted at low-risk people while best welfare outcomes are achieved when tax subsidies are targeted at low-income people.

Several papers study the effects of the tax exclusion reform but none of them investigates the possibilities of targeting the tax subsidy. Gruber (2011) uses a micro-simulation model to evaluate the effect of the tax exclusion removal and finds that this reform substantially increases government revenue but also significantly decreases the insurance

\footnotetext{
${ }^{2}$ Since medical expenditures are persistent people with low current medical expenses have lower expected expenses and thus they drive down the average premium in the employer-based market.
} 
coverage. Azawa and Fang (2012) focus on firms' decisions to offer health insurance and find that the removal of the tax exclusion slightly reduces the number of firms offering employer-based insurance. Huang and Huffman (2010) evaluate the effects of the tax exclusion removal using a general equilibrium search model. They find that this reform increases unemployment by reducing search effort. Jeske and Kitao (2009) address this question using a stochastic aging general equilibrium model featuring individuals heterogeneous in their medical expense shocks. They find that the complete elimination of the tax exclusion results in a partial collapse of the employer-based market due to the adverse selection problem. Similar to Jeske and Kitao (2009) we focus on individual decisions related to health insurance but we also allow for a full life cycle and endogenous labor supply. This framework is well-suited to study possible feedback effects through changing the composition of the ESHI pool after the tax exclusion reform which can trigger the adverse selection spiral if healthy and young participants start leaving the pool.

Our paper belongs to a growing literature that augments the standard incomplete market model with medical expense shocks and health insurance markets. Among others this literature includes Hansen et al (2011) who evaluate the quantitative effects of introducing Medicare buy-in, Hsu (2012) who studies the effect of health insurance on savings, Pashchenko and Porapakkarm (2011) who examine the importance of the reclassification risk in the health insurance market.

We also contribute to the literature that examines the implications of government policies related to health and health insurance market. This includes Attanasio, Kitao and Violante (2011), Hai (2012), Kim (2012), Ozkan (2012), St-Amour (2012), Zhao (2011). More broadly, we relate to the literature that studies the life-cycle behavior of individuals in the presence of health uncertainty. This includes Capatina (2011), De Nardi et al (2010), French and Jones (2011), Kopecky and Koreshkova (2012), Prados (2012).

The paper is organized as follows. Section 2 describes a simple model that illustrates the intuition behind our results. Section 3 introduces the full model. Section 4 describes the calibration. Section 5 evaluates the performance of the baseline model. Section 6 describes the results. Section 7 concludes.

\section{Simple Illustration}

In this section we construct a simple model to illustrate the intuition behind our results. In this simple framework we show how different subsidy schemes can be used to keep together an insurance pool of individuals heterogeneous in their risks.

Consider a continuum of individuals who differ in their expected medical costs. We denote an actuarial fair insurance price of an individual $i$ by $p_{i}$. Assume $p_{i}$ is uniformly 
distributed over the interval $\left[0, p_{H}\right], p_{i} \sim F(p)$. If all individuals participate in one insurance pool the price in this pool will be equal to $\bar{p}=\int_{0}^{p_{H}} p d F(p)=\frac{p_{H}}{2}$. However, this pool is unstable because individuals with $p_{i}<\bar{p}$ want to drop out. To prevent the unraveling we need to introduce subsidies. Consider first the case where the size of the subsidy cannot be differentiated, i.e. every individual gets the same subsidy in the amount $s$. In this case to ensure full participation the subsidy should be equal to $\bar{p}$ to make an individual with the lowest $p_{i}=0$ indifferent between staying or leaving, i.e.

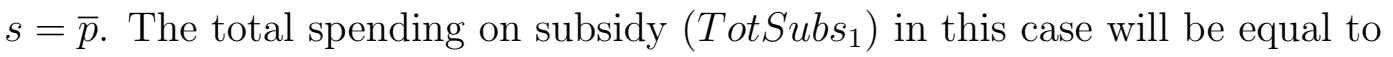

$$
\operatorname{TotSubs}_{1}=\int_{0}^{p_{H}} s d F(p)=\bar{p}=\frac{p_{H}}{2}
$$

Second, consider the situation where the size of the subsidy can be differentiated. In this case each individual gets a subsidy $s_{i}=\max \left\{0, \bar{p}-p_{i}\right\}$. Thus, only individuals with $p_{i}<\bar{p}$ will get the subsidy and the size of the subsidy is decreasing in $\bar{p}-p_{i}$. The total spending on subsidies is equal to

$$
\text { TotSubs }_{2}=\int_{0}^{p_{H}} s_{i} d F(p)=\frac{p_{H}}{8}
$$

Note that the total spending on subsidies can be cut four times by taking into account that individuals differ in their incentives to participate in the pool.

Now assume that instead of one there are two pools: people with $p_{i}<\bar{p}$ participate in the first pool, and people with $p_{i} \geq \bar{p}$ - in the second pool. The prices in the first pool $\left(\bar{p}_{1}\right)$ and in the second pool $\left(\bar{p}_{2}\right)$ are determined in the following way:

$$
\bar{p}_{1}=\frac{1}{\operatorname{Pr}(p<\bar{p})} \int_{0}^{\bar{p}} p d F(p)=\frac{p_{H}}{4} \quad \text { and } \quad \bar{p}_{2}=\frac{1}{\operatorname{Pr}(p \geq \bar{p})} \int_{\bar{p}}^{p_{H}} p d F(p)=\frac{3 p_{H}}{4}
$$

Here $\operatorname{Pr}(p<\bar{p})(\operatorname{Pr}(p \geq \bar{p}))$ is the probability that $p$ is less (greater or equal) to $\bar{p}$. Consider the total subsidy spending needed to ensure full participation in each pool. If the subsidy is uniform, each individual in the first pool should get subsidy equal to $\bar{p}_{1}-0=\frac{p_{H}}{4}$, and each individual in the second pool should receive $\bar{p}_{2}-\bar{p}=\frac{p_{H}}{4}$. Thus, total spending to keep the pools together are:

$$
\operatorname{TotSubs}_{3}=\frac{p_{H}}{4} \int_{0}^{\bar{p}} d F(p)+\frac{p_{H}}{4} \int_{\bar{p}}^{p_{H}} d F(p)=\frac{p_{H}}{4}
$$


In case of the differentiated subsidy, people in the first pool get a subsidy equal to $s_{i}^{1}=\max \left\{0, \bar{p}_{1}-p_{i}\right\}$ and people in the second pool $-s_{i}^{2}=\max \left\{0, \bar{p}_{2}-p_{i}\right\}$. This results in the total subsidy spending equal to

$$
\text { TotSubs }_{4}=\int_{0}^{\bar{p}_{1}} s_{i}^{1} d F(p)+\int_{\bar{p}}^{\bar{p}_{2}} s_{i}^{2} d F(p)=\frac{p_{H}}{16}
$$

Table 1 summarizes the total subsidy spending in four cases considered above. The important result is that moving from the uniform to differentiated subsidy can substantially reduce the total spending needed to ensure full participation in the pool. These savings arise from withdrawing subsidies from people who are willing to participate even when not subsidized, i.e. people with $p_{i}>\bar{p}$. Another result is that it is much cheaper to ensure the participation of all individuals if instead of one big pool there are two smaller pools. This happens because in the two smaller pools people are less heterogeneous in their risks and thus the size of cross-subsidization from low risk to high risk is smaller. In particular, in the one big pool the difference in risk-adjusted premiums between high and low risks is $p_{H}$, while in the two smaller pools this difference is $\bar{p}=p_{H}-\bar{p}=p_{H} / 2$. Because of this smaller direct subsidy is needed to make low risk people willing to crosssubsidize high risk people.

\begin{tabular}{|c|c|c|}
\hline & One Pool & Two pools \\
\hline Uniform subsidy & $p_{H} / 2$ & $p_{H} / 4$ \\
Differentiated subsidy & $p_{H} / 8$ & $p_{H} / 16$ \\
\hline
\end{tabular}

Table 1: Total spending on subsidies for different subsidy schemes

\section{Baseline Model}

\subsection{Households}

\subsubsection{Demographics and preferences}

The economy is populated by overlapping generations of individuals. An individual lives to a maximum of $N$ periods. During the first $R-1$ periods of life an individual can choose whether to work or not; at age $R$ all individuals retire. We denote the labor supply decision of a household by $l_{t}, l_{t} \in\{0, \bar{l}\}$.

Agents are endowed with one unit of time that can be used for either leisure or work. There is a fixed cost of work $\phi_{t, e}$ treated as a loss of leisure. Thus working individuals' leisure time can be expressed as $1-\bar{l}-\phi_{t, e}$. The fixed cost of work depends on age 
$(t)$ and education $(e)$. In addition, individuals in bad health incur higher costs of work: $\phi_{t, e}=\phi_{1}(t, e)+\phi_{2}(t, e) \mathbf{1}_{\{\text {health=bad\} }}$ where $\mathbf{1}_{\{.\}}$is an indicator function mapping to one if its argument is true, while $\phi_{1}(t, e)$ and $\phi_{2}(t, e)$ are non-negative functions.

We assume Cobb-Douglas specification for preferences over consumption and leisure:

$$
u\left(c_{t}, l_{t}\right)=\frac{\left(c_{t}^{\chi}\left(1-l_{t}-\phi_{t, e} \mathbf{1}_{\left\{l_{t}>0\right\}}\right)^{1-\chi}\right)^{1-\sigma}}{1-\sigma} .
$$

Here $\chi$ is a parameter determining the relative importance of consumption, and $\sigma$ is the risk-aversion over the consumption-leisure composite.

Agents discount the future at the rate $\beta$ and survive till the next period with conditional probability $\zeta_{t}$, which depends on age and health. We assume that the savings (net of out-of-pocket medical expenses) of each household who does not survive are equally allocated among all survived agents of a working age within the same educational group. The population grows at the rate $\eta$.

\subsubsection{Health expenditures and health insurance}

Each period an agent faces a stochastic medical expenditure shock $x_{t}$. Medical shocks evolve according to a Markov chain $\mathcal{G}\left(x_{t+1} \mid x_{t}, t\right)$. We categorize individuals into two groups according to their medical expenses. Individuals with low medical expenses $\left(x_{t} \leq\right.$ $\left.\overline{x_{t}}\right)$ are referred to as 'healthy' or 'people in good health', while individuals with high medical expenses $\left(x_{t}>\overline{x_{t}}\right)$ are referred to as 'unhealthy' or 'people in bad health'. Here $\overline{x_{t}}$ is a threshold separating people into these two groups.

Every individual of working age can buy health insurance (HI) against a medical shock in the individual health insurance market. The price of health insurance in the individual market is a function of an agent's current medical shock and age, and is denoted by $p_{I}\left(x_{t}, t\right)$.

Every period with some probability $\mathrm{Prob}_{t}$ an agent of working age gets an offer to buy employer-sponsored health insurance (ESHI). The variable $g_{t}$ characterizes the status of the offer: $g_{t}=1$ if an individual gets an offer, and $g_{t}=0$ if he does not. All participants of the employer-based pool are charged the same premium $p$ regardless of their current medical expenses and age. An employer pays a fraction $\psi$ of this premium. If the worker chooses to buy group insurance, he only pays $\bar{p}$ where:

$$
\bar{p}=(1-\psi) p
$$

Low-income individuals of working age can obtain their health insurance from Medicaid for free. There are two pathways to qualify for Medicaid. First, an individual can become eligible if his total income is below threshold $y^{\text {cat }}$. Second, an individual can 
become eligible through the Medically Needy program. This happens if his total income minus medical expenses is below threshold $y^{\text {need }}$ and his assets are less than the limit $k^{p u b}$.

We use $i_{t}$ to index the current health insurance status as follows:

$$
i_{t}=\left\{\begin{array}{ll}
0 & ; \text { if uninsured } \\
1 & ; \text { if insured by Mediciad } \\
2 & ; \text { if privately insured }
\end{array}\right\}
$$

All types of insurance contracts - group, individual, and public - provide only partial insurance against medical expenditure shocks. We denote by $q\left(x_{t}, i_{t}\right)$ the fraction of medical expenditures covered by the insurance contract. This fraction is a function of medical expenditures and the type of insurance a household has.

All retired households are enrolled in the Medicare program. The Medicare program charges a fixed premium of $p_{\text {med }}$ and covers a fraction $q_{\text {med }}$ of medical costs.

\subsubsection{Labor income}

Households differ by their educational attainment $e$. Educational attainment can take two values: $e=1$ corresponds to the absence of any degree, $e=2$ corresponds to at least a high-school degree. Earnings are equal to $\widetilde{w} z_{t}^{e, x} l_{t}$, where $\widetilde{w}$ is wage and $z_{t}^{e, x}$ is the idiosyncratic productivity that depends on educational level $(e)$, age $(t)$ and medical expenses $\left(x_{t}\right)$ of an individual.

\subsubsection{Taxation and social transfers}

All households pay income taxes that consist of two parts: a progressive tax denoted by $\mathcal{T}\left(y_{t}\right)$ and a proportional tax denoted by $\tau_{y} .{ }^{3}$ Taxable income $y_{t}$ is based on both labor and capital income. Working households also pay payroll taxes - Medicare tax $\left(\tau_{\text {med }}\right)$ and Social Security tax $\left(\tau_{s s}\right)$. The Social Security tax rate for earnings above $\bar{y}_{s s}$ is zero. The U.S. tax code allows households to subtract out-of-pocket medical expenditures that exceed $7.5 \%$ of their income when the taxable income is calculated. In addition, ESHI premium $(\bar{p})$ is excluded from taxable income for both income and payroll taxes. Consumption is taxed at a proportional rate $\tau_{c}$.

We also assume a public safety-net program, $T_{t}^{S I}$. The program guarantees that every household will have a minimum consumption level at $\underline{c}$. This reflects the option available to U.S. households with a bad combination of income and medical shocks to rely on

\footnotetext{
${ }^{3}$ The progressive part $\mathcal{T}\left(y_{t}\right)$ approximates the actual income tax schedule in the U.S., while the proportional tax represents all other taxes that we do not model explicitly. In this approach we follow Jeske and Kitao (2009).
} 
public transfer programs such as food stamps, Supplemental Security Income, and uncompensated care. ${ }^{4}$ Retired households receive Social Security benefits $s s_{e}$ that depend on educational attainment $e$.

\subsubsection{Optimization problem}

Households of a working age $(t<R)$ The state variables for the working age household's optimization problem are capital $\left(k_{t} \in \mathbb{K}=R^{+} \cup\{0\}\right)$, medical cost shock $\left(x_{t} \in \mathbb{X}=R^{+} \cup\{0\}\right)$, idiosyncratic labor productivity $\left(z_{t}^{e, x} \in \mathbb{Z}=R^{+}\right)$, ESHI offer status $\left(g_{t} \in \mathbb{G}=\{0,1\}\right)$, health insurance status $\left(i_{t} \in \mathbb{I}=\{0,1,2\}\right)$, educational attainment $(e \in \mathbb{E}=\{1,2\})$ and age $(t)$.

In each period a household chooses consumption $\left(c_{t}\right)$, labor supply $\left(l_{t}\right)$, savings $\left(k_{t+1}\right)$, and health insurance status for the next period $\left(i_{H}^{\prime}\right)$. If he is eligible for Medicaid, he can get free public insurance (we call this option $M$ ). If he works in a firm offering an ESHI, he can buy a group insurance $(G)$. In addition, everyone can choose to be uninsured $(U)$, or buy individual insurance $(I)$. We can summarize insurance choices as follows. If an individual is eligible for Medicaid:

$$
i_{H}^{\prime}=\left\{\begin{array}{ll}
\{M, I, G\} & ; \text { if } g_{t}=1 \text { and } l_{t}>0 \\
\{M, I\} & ; \text { if } g_{t}=0 \text { or } l_{t}=0
\end{array}\right\}
$$

Otherwise

$$
i_{H}^{\prime}=\left\{\begin{array}{ll}
\{U, I, G\} & \text { if } g_{t}=1 \text { and } l_{t}>0 \\
\{U, I\} & ; \text { if } g_{t}=0 \text { or } l_{t}=0
\end{array}\right\} .
$$

The value function of a working-age individual can be written as follows:

$$
V_{t, e}\left(k_{t}, x_{t}, z_{t}^{e, x}, g_{t}, i_{t}\right)=\max _{k_{t+1}, c_{t}, l_{t}, i_{H}^{\prime}} u\left(c_{t}, l_{t}\right)+\beta \zeta_{t} E_{t} V_{t+1, e}\left(k_{t+1}, x_{t+1}, z_{t+1}^{e, x}, g_{t+1}, i_{t+1}\right)
$$

subject to

$$
k_{t}(1+r)+\widetilde{w} z_{t}^{e, x} l_{t}+T_{t}^{S I}+B e q_{e}=\left(1+\tau_{c}\right) c_{t}+k_{t+1}+x_{t}\left(1-q\left(x_{t}, i_{t}\right)\right)+P_{t}+\text { Tax }
$$

\footnotetext{
${ }^{4}$ In $200485 \%$ of uncompensated care were paid by the government. The major portion is sourced from the disproportionate share hospital (DSH) payment (Kaiser Family Foundation, 2004).
} 


$$
\begin{aligned}
& \widetilde{w}=\left\{\begin{array}{lll}
w & ; & \text { if } g_{t}=0 \\
\left(w-c_{E}\right) & ; & \text { if } g_{t}=1
\end{array}\right\} \\
& P_{t}=\left\{\begin{array}{cll}
0 & ; & \text { if } i_{H}^{\prime} \in\{U, M\} \\
p_{I}\left(x_{t}, t\right) & ; & \text { if } i_{H}^{\prime}=I \\
\bar{p} & ; & \text { if } i_{H}^{\prime}=G
\end{array}\right\} \\
& i_{t+1}=\left\{\begin{array}{l}
0 ; \text { if } i_{H}^{\prime}=U \\
1 ; \text { if } i_{H}^{\prime}=M \\
2 ; \text { if } i_{H}^{\prime} \in\{I, G\}
\end{array}\right\} \\
& \operatorname{Tax}=\mathcal{T}\left(y_{t}\right)+\tau_{y} y_{t}+\tau_{\text {med }}\left(\widetilde{w} z_{t}^{e, x} l_{t}-\bar{p} \mathbf{1}_{\left\{i_{H}^{\prime}=G\right\}}\right)+\tau_{s s} \min \left(\widetilde{w} z_{t}^{e, x} l_{t}-\bar{p} \mathbf{1}_{\left\{i_{H}^{\prime}=G\right\}}, \bar{y}_{s s}\right) \\
& y_{t}=r k_{t}+\widetilde{w} z_{t}^{e, x} l_{t}-\bar{p} \mathbf{1}_{\left\{i_{H}^{\prime}=G\right\}}-\max \left(0, x_{t}\left(1-q\left(x_{t}, i_{t}\right)\right)-0.075\left(\widetilde{w} z_{t}^{e, x} l_{t}+r k_{t}\right)\right) \\
& T_{t}^{S I}=\max \left(0,\left(1+\tau_{c}\right) \underline{c}+x_{t}\left(1-q\left(x_{t}, i_{t}\right)\right)+T a x-\widetilde{w} z_{t}^{e, x} l_{t}-k_{t}(1+r)-B e q_{e}\right) .
\end{aligned}
$$

An individual is eligible for Medicaid if

$$
\begin{gathered}
\left\{\begin{array}{c}
y_{t}^{\text {tot }} \leq y^{c a t} \quad \text { or } \\
y_{t}^{\text {tot }}-x_{t}\left(1-q\left(x_{t}, i_{t}\right)\right) \leq y^{\text {need }} \text { and } k_{t} \leq k^{p u b}
\end{array}\right\} \\
y_{t}^{\text {tot }}=r k_{t}+\widetilde{w} z_{t}^{e, x} l_{t}
\end{gathered}
$$

The conditional expectation on the right-hand side of Equation (3) is over $\left\{x_{t+1}, z_{t+1}^{e, x}, g_{t+1}\right\}$. Equation (4) is the budget constraint. $B e q_{e}$ is accidental bequest. In Equation (5), $w$ is wage per effective labor unit. If the household has an ESHI offer, his employer pays part of his insurance premium. To maintain zero profit condition, the employer who offers ESHI deducts an amount $c_{E}$ from the wage per effective labor unit, as shown in (5). Equation (7) maps the current HI choice into the next period HI status. In Equation (8), the first two terms are income taxes and the last two terms are payroll taxes. ${ }^{5}$ Note that both employer's and employee's contributions towards the ESHI premium are excluded from taxable income.

Retired households For a retired household $(t \geq R)$ the state variables are capital $\left(k_{t}\right)$, medical expenses shock $\left(x_{t}\right)$, educational attainment $(e)$, and age $(t){ }^{6}$

$$
V_{t, e}\left(k_{t}, x_{t}\right)=\max _{k_{t+1}, c_{t}} u\left(c_{t}, 0\right)+\beta \zeta_{t} E_{t} V_{t+1, e}\left(k_{t+1}, x_{t+1}\right)
$$

\footnotetext{
${ }^{5}$ In practice, employers contribute $50 \%$ of Medicare and Social Security taxes. For simplicity, we assume that employees pay $100 \%$ of payroll taxes.

${ }^{6}$ The problem of a just retired household is slightly different since he is still under insurance coverage from the previous period. Thus, $i_{t}$ is an additional state variable and out-of-pocket medical expenses are $x_{t}\left(1-q\left(x_{t}, i_{t}\right)\right)$.
} 
subject to

$$
\begin{gathered}
k_{t}(1+r)+s s_{e}+T_{t}^{S I}=\left(1+\tau_{c}\right) c_{t}+k_{t+1}+x_{t}\left(1-q_{\text {med }}\right)+p_{\text {med }}+\text { Tax } \\
\operatorname{Tax}=\mathcal{T}\left(y_{t}\right)+\tau_{y} y_{t} \\
y_{t}=r k_{t}+s s_{e}-\max \left(0, x_{t}\left(1-q_{\text {med }}\right)-0.075\left(s s_{e}+r k_{t}\right)\right) \\
T_{t}^{S I}=\max \left(0,\left(1+\tau_{c}\right) \underline{c}+x_{t}\left(1-q_{\text {med }}\left(x_{t}\right)\right)+\text { Tax }+p_{\text {med }}-s s_{e}-k_{t}(1+r)\right) .
\end{gathered}
$$

Distribution of households To simplify the notation, let $\mathbb{S}$ define the space of a household's state variables, where $\mathbb{S}=\mathbb{K} \times \mathbb{Z} \times \mathbb{X} \times \mathbb{G} \times \mathbb{I} \times \mathbb{E} \times \mathbb{T}$ for working-age households and $\mathbb{S}=\mathbb{K} \times \mathbb{X} \times \mathbb{E} \times \mathbb{T}$ for retired households. Let $\mathbf{s} \in \mathbb{S}$, and denote by $\Gamma(\mathbf{s})$ the distribution of households over the state-space.

\subsection{Production sector}

There are two stand-in firms which act competitively. Their production functions are Cobb-Douglas, $A K^{\alpha} L^{1-\alpha}$, where $K$ and $L$ are aggregate capital and aggregate labor and $A$ is the total factor productivity. The first stand-in firm offers ESHI to its workers but the second stand-in firm does not. Under competitive behavior, the second firm pays each employee his marginal product of labor. Since capital is freely allocated between the two firms, the Cobb-Douglas production function implies that the capital-labor ratios of both firms are the same. Consequently, we have

$$
\begin{aligned}
& w=(1-\alpha) A K^{\alpha} L^{-\alpha}, \\
& r=\alpha A K^{\alpha-1} L^{1-\alpha}-\delta,
\end{aligned}
$$

where $\delta$ is the depreciation rate.

The first firm has to partially finance the health insurance premium for its employees. These costs are passed on to its employees through a wage reduction. In specifying this wage reduction, we follow Jeske and Kitao (2009). The first firm subtracts an amount $c_{E}$ from the marginal product per effective labor unit. The zero profit condition implies

$$
c_{E}=\frac{\psi p\left(\int \mathbf{1}_{\left\{i_{H}^{\prime}(s)=G\right\}} \Gamma(\boldsymbol{s})\right)}{\int l_{t} z_{t}^{e, x} \mathbf{1}_{\left\{g_{t}=1\right\}} \Gamma(\boldsymbol{s})} .
$$

The numerator is the total contributions towards insurance premiums paid by the first firm. The denominator is the total effective labor working in the first firm. 


\subsection{Insurance sector}

Health insurance companies in both private and group markets act competitively. We assume that insurers can observe all state variables that determine future medical expenses of the individuals. This assumption, together with zero profit conditions, allows us to write insurance premiums in the following way:

$$
p_{I}\left(x_{t}, t\right)=(1+r)^{-1} \gamma E M\left(x_{t}, t\right)+\pi
$$

for the non-group insurance market and

$$
p=(1+r)^{-1} \frac{\gamma\left(\int \mathbf{1}_{\left\{i_{H}^{\prime}(\mathbf{s})=G\right\}} E M\left(x_{t}, t\right) \Gamma(s)\right)}{\int 1_{\left\{i_{H}^{\prime}(\mathbf{s})=G\right\}} \Gamma(s)}
$$

for the group insurance market. Here, $E M\left(x_{t}, t\right)$ is the expected medical cost of an individual of age $t$ and with current medical costs $x_{t}$ that will be covered by the insurance company:

$$
E M\left(x_{t}, t\right)=\int x_{t+1} q\left(x_{t+1}, 2\right) \mathcal{G}\left(x_{t+1} \mid x_{t}, t\right) .
$$

$\gamma$ is a markup on prices due to the administrative costs in the individual and group markets; $\pi$ is the fixed costs of buying an individual policy. ${ }^{7}$ The premium in the nongroup insurance market is based on the discounted expected medical expenditure of an individual buyer. The premium for group insurance is based on a weighted average of the expected medical costs of those who buy group insurance.

\subsection{Government constraint}

We assume that the government runs a balanced budget. This implies

$$
\begin{gathered}
\int\left[\operatorname{Tax}(\boldsymbol{s})+\tau_{c} c_{t}(\boldsymbol{s})\right] \Gamma(\boldsymbol{s})-G= \\
\int_{t \geq R}\left[s s_{e}+q_{\text {med }} x_{t}-p_{\text {med }}\right] \Gamma(\boldsymbol{s})+\int T_{t}^{S I} \Gamma(\boldsymbol{s})+\int_{t<R} \mathbf{1}_{\left\{i_{H}^{\prime}=M\right\}} q\left(x_{t}, 1\right) x_{t} \Gamma(\boldsymbol{s})
\end{gathered}
$$

The left-hand side is the total tax revenue from all households net of the exogenous government expenditures $(G)$. The first term on the right-hand side is the net expenditures on Social Security and Medicare for retired households. The second term is the costs of guaranteeing the minimum consumption floor for households. The last term is the costs of Medicaid.

\footnotetext{
${ }^{7}$ Fixed costs capture the difference in overhead costs for individual and group policies.
} 


\subsection{Definition of stationary competitive equilibrium}

Given the government programs $\left\{\underline{c}, s s_{e}, q_{\text {med }}, p_{\text {med }}, y^{c a t}, y^{\text {need }}, k^{p u b}, G\right\}$, the fraction of medical costs covered by private insurers and Medicaid $\left\{q\left(x_{t}, i_{t}\right)\right\}$, and the employers' contribution $(\psi)$, the competitive equilibrium of this economy consists of the set of time-invariant prices $\left\{w, r, p, p_{I}\left(x_{t}, t\right)\right\}$, wage reduction $\left\{c_{E}\right\}$, households' value functions $\left\{V_{t, e}(\boldsymbol{s})\right\}$, decision rules of working-age households $\left\{k_{t+1}(\boldsymbol{s}), c_{t}(\boldsymbol{s}), l_{t}(\mathbf{s}), i_{H}^{\prime}(\boldsymbol{s})\right\}$ and retired households $\left\{c_{t}(\boldsymbol{s}), k_{t+1}(\boldsymbol{s})\right\}$ and the tax functions $\left\{\mathcal{T}(y), \tau_{\text {med }}, \tau_{s s}, \tau_{c}, \tau_{y}\right\}$ such that the following conditions are satisfied:

1. Given the set of prices and the tax functions, the decision rules solve the households' optimization problems in equations (3) and (11).

2. Wage $(w)$ and rent $(r)$ satisfy equation (12) and (13), where

$$
\begin{aligned}
K & =\int k_{t+1}(\mathbf{s}) \Gamma(\mathbf{s})+\int_{t<R}\left[\mathbf{1}_{\left\{i_{H}^{\prime}(\mathbf{s})=G\right\}} p+\mathbf{1}_{\left\{i_{H}^{\prime}(\mathbf{s})=I\right\}}\left(p_{I}(x, t)-\pi\right)\right] \Gamma(\boldsymbol{s}), \\
L & =\int_{t<R} z_{t}^{e, x} l_{t}(\mathbf{s}) \Gamma(\mathbf{s}) .
\end{aligned}
$$

3. $c_{E}$ satisfies equation (14), thus the firm offering ESHI earns zero profit.

4. The non-group insurance premiums $p_{I}\left(x_{t}, t\right)$ satisfy equation (15), and the group insurance premium satisfies equation (16), so health insurance companies earn zero profit.

5. The tax functions $\left\{\mathcal{T}(y), \tau_{\text {med }}, \tau_{s s}, \tau_{c}, \tau_{y}\right\}$ balance the government budget (17).

\section{Data and calibration}

\subsection{Data}

We calibrated the model using the Medical Expenditure Panel Survey (MEPS) dataset. The MEPS collects detailed records on demographics, income, medical costs and insurance for a nationally representative sample of households. It consists of two-year overlapping panels and covers the period of 1996-2008. We use nine waves of the MEPS from 1999 to 2008.

The MEPS links people into one household based on eligibility for coverage under a typical family insurance plan. This Health Insurance Eligibility Unit (HIEU) defined in the MEPS dataset corresponds to our definition of a household. All statistics we use were computed for the head of the HIEU. We define the head as the male with the highest 
income in the HIEU. If the HIEU does not have a male member we assign a female with the highest income as its head. We use longitudinal weights provided in the MEPS to compute all the statistics. Since each wave is a representation of population in each year, the weight of each individual was divided by nine in the pooled sample.

In our sample we include all household heads who are at least 24 years old and have non-negative labor income (to be defined later). We use 2002 as the base year. All level variables were normalized to the base year using Consumer Price Index (CPI).

\subsection{Demographics, preferences and technology}

In the model, agents are born at age 25 and can live to a maximum age of 99 . The model period is one year so the maximum lifespan $N$ is 75 . Agents retire at the age of 65 , so $R$ is 41 .

To adjust conditional survival probabilities $\zeta_{t}$ for the difference in medical expenses we follow Attanasio et al. (2011). In particular, we use Health and Retirement Survey (HRS) and MEPS to estimate the difference in survival probabilities for people in different medical expense categories and use it to adjust the male life tables from the Social Security Administration. ${ }^{8}$ The population growth rate was set to $1.35 \%$ to match the fraction of people older than 65 in the data.

We set the consumption share in the utility function $\chi$ to 0.6 using the estimates of French (2005). ${ }^{9}$ The parameter $\sigma$ is set to 5 which corresponds to the risk-aversion over consumption equal to 3.4 which is in the range commonly used in the life-cycle literature. ${ }^{10}$ The discount factor $\beta$ is calibrated to match the aggregate capital output ratio of 3 . We set labor supply of those who choose to work $(\bar{l})$ to 0.4

Fixed leisure costs of work $\phi_{t, e}$ are calibrated to match the employment profiles in each educational and health group. ${ }^{11}$ More specifically, we assume that fixed costs for people in good health $\phi_{1}(t, e)$ do not vary with age and use this parameter to match the employment rate for the age group 55-59 for each educational group. For the additional fixed costs of people with bad health $\phi_{2}(t, e)$, we assume it is a linear function of age. For each educational group we adjust the intercept and the slope of this function to match two moments: the employment rate of people in the 25-29 and 55-59 age groups who have bad health. The resulting fixed costs are presented in Table 2.

The Cobb-Douglas function parameter $\alpha$ is set at 0.33 , which corresponds to the

\footnotetext{
${ }^{8}$ more details are available in Pashchenko and Porapakkarm (2012).

${ }^{9}$ Given that we have indivisible labor supply we cannot pin down this parameter using a moment in the data.

${ }^{10}$ The relative risk aversion over consumption is given by $-c u_{c c} / u_{c}=1-\chi(1-\sigma)$.

${ }^{11}$ We define a person as employed if he works at least 520 hours per year, earns at least $\$ 2,678$ per year in base year dollars (this corresponds to working at least 10 hours per week and earning a minimum wage of $\$ 5.15$ per hour), and does not report being retired or receiving Social Security benefits.
} 


\begin{tabular}{|l|c|c|}
\hline \hline & High-school dropouts & HS and College graduates \\
\hline$\phi_{1}$ & 0.2800 & 0.2650 \\
$\phi_{2}$ intercept & 0.0200 & 0.0450 \\
$\phi_{2}$ slope & 0.0008 & 0.0025 \\
\hline \hline
\end{tabular}

Table 2: Parameters characterizing disutility from work

capital income share in the US. The annual depreciation rate $\delta$ is calibrated to achieve an interest rate of $4 \%$ in the baseline economy. The total factor productivity $\mathrm{A}$ is set such that the total output equals one in the baseline model.

\subsection{Government}

In calibrating the tax function $\mathcal{T}(y)$ we use a nonlinear function specified by Gouveia and Strauss (1994):

$$
\mathcal{T}(y)=a_{0}\left[y-\left(y^{-a_{1}}+a_{2}\right)^{-1 / a_{1}}\right]
$$

This functional form is commonly used in the quantitative macroeconomic literature (for example, Conesa and Krueger, 2006; Jeske and Kitao, 2009). In this functional form $a_{0}$ controls the marginal tax rate faced by the highest income group, $a_{1}$ determines the curvature of marginal taxes and $a_{2}$ is a scaling parameter. We set $a_{0}$ and $a_{1}$ to the original estimates as in Gouveia and Strauss (1994), which are 0.258 and 0.768 correspondingly. The parameter $a_{2}$ is used to balance the government budget in the baseline economy. We set proportional income tax $\tau_{y}$ to $6.62 \%$ to match the fact that around $65 \%$ of tax revenues come from income taxes that are approximated in our calibration by the progressive function $\mathcal{T}(y)$. When considering the tax exclusion reform we keep $a_{2}$ fixed at the level that balances the budget in the baseline economy, and we adjust the parameter $\tau_{y}$ to achieve the balanced budget.

The minimum consumption floor $\underline{c}$ was set to $\$ 2,700$ following the estimates of De Nardi et al. (2010). The Social Security replacement rates were set to $40 \%$ and $30 \%$ of the average labor income for people with low and high education correspondingly, reflecting the progressivity of the system.

Medicaid eligibility rules were taken from the data. The income eligibility threshold for general Medicaid ( $y^{c a t}$ ) is set to $64 \%$ of FPL which is the median value for this threshold among all states in 2009. The income eligibility threshold for the Medically Needy program $\left(y^{\text {need }}\right)$ and asset test for this program $\left(k^{p u b}\right)$ are set to $53 \%$ of FPL and $\$ 2,000$ correspondingly. These numbers are equal to the median values for the corresponding eligibility criteria in 2009 in the states that have Medically Needy program.

The Medicare, Social Security and consumption tax rates were set to $2.9 \%, 12.4 \%$ 
and $5.67 \%$ correspondingly. The maximum taxable income for Social Security is set to $\$ 84,900$. The fraction of exogenous government expenses in GDP is $18 \%$.

\subsection{Insurance sector}

The share of health insurance premium paid by the firm $(\psi)$ was chosen to match the aggregate ESHI take-up rate. ${ }^{12}$ The resulting number $(76.3 \%)$ is consistent with the one observed in the U.S. economy, which is in the range of $75-85 \%$ (Kaiser Family Foundation, 2009).

We set the proportional loads for group and individual insurance policies $(\gamma)$ to 1.11 (Kahn et al., 2005). The fixed costs of buying an individual policy $\pi$ is set to $\$ 23$ to match the aggregate fraction of people with individual insurance.

\subsection{Offer rate}

We assume that probability of getting an offer of ESHI coverage is a logistic function:

$$
\operatorname{Prob}_{t}=\frac{\exp \left(u_{t}\right)}{1+\exp \left(u_{t}\right)}
$$

where the variable $u_{t}$ is an odds ratio that takes the following form:

$$
u_{t}=\eta_{0}^{e}+\eta_{1}^{e} \log \left(i n c_{t}\right)+\eta_{2}^{e}\left[\log \left(i n c_{t}\right)\right]^{2}+\eta_{3}^{e}\left[\log \left(i n c_{t}\right)\right]^{3}+\eta_{4}^{e} \mathbf{1}_{\left\{g_{t-1}=1\right\}}+\Theta^{e} D_{t}
$$

Here $\eta_{0}^{e}, \eta_{1}^{e}, \eta_{2}^{e}, \eta_{3}^{e}, \eta_{4}^{e}$ and $\Theta^{e}$ are education-specific coefficients, $i n c_{t}$ is individual labor income (normalized by the average labor income), and $D_{t}$ is a set of year dummy variables. To construct the initial offer rate $\left(g_{1}\right.$ in equation (18) $)$ we run a separate logistic regression for people aged 24-26 where we do not include offer in the previous period but include dummies for medical expenses categories.

\subsection{Insurance status}

In the MEPS the question about the source of insurance coverage is asked retrospectively for each month of the year. We define a person as having employer-based insurance if he reports having ESHI for at least eight months during the year (variables PEGJA-PEGDE). The same criterion is used when defining public insurance (variables PUBJA-PUBDE) and individual insurance status (variables PRIJA-PRIDE). For those few individuals who switch sources of coverage during a year, we use the following definition of insurance status. If a person has both ESHI and individual insurance in one year,

\footnotetext{
${ }^{12}$ In this paper we use the term "take-up rate" only in relation to the employer-based market, and it defines the fraction of people among those with an ESHI offer who choose to buy group insurance.
} 
and each coverage lasted for less than eight months, but the total duration of coverage lasted for more than eight months, we classify this person as individually insured. Likewise, when a person has a combination of individual and public coverage that altogether lasts for more than eight months, we define that individual as having public insurance. ${ }^{13}$

\subsection{Medical expenditures}

Medical costs in our model correspond to the total paid medical expenditures in the MEPS dataset (variable TOTEXP). These include not only out-of-pocket medical expenses but also the costs covered by insurers. In our calibration medical expense shock is approximated by a 5-state discrete Markov process. For each age, we divide medical expenditures into 5 bins, corresponding to 30th, 60th, 90th and 99th percentiles. ${ }^{14}$ We set $\overline{x_{t}}$ that separates people into different medical expenses categories to the 90th percentile of medical expenses distribution of the corresponding age. In other words, people whose medical expenses are in the lowest three bins are classified as healthy, while people whose medical expenses are in the highest two bins are classified as unhealthy. To construct the transition matrix we measure the fraction of people who move from one bin to another between two consecutive years separately for people of working age (25-64) and for retirees (older than 65).

We use MEPS to estimate the fraction of medical expenses covered by insurance policies $q\left(x_{t}, i_{t}\right)$. We find that Medicaid provides better coverage than private insurance for low medical expenses but for higher expenses private insurance is more generous. For retired households we set $q_{\text {med }}$ to 0.5 following Jeske and Kitao (2009) and Attanasio et al (2011).

\subsection{Labor income}

We divide households into two educational groups: high-school dropouts and people with at least a high-school degree. The fraction of each group in the population is $15 \%$ and $85 \%$ correspondingly. Individuals with different education and health have different productivity, specified as follows:

$$
z_{t}^{e, x}=\lambda_{t}^{e, x} \exp \left(v_{t}\right) \exp \left(\xi_{t}\right)
$$

where $\lambda_{t}^{e, x}$ is the deterministic function of age, education and medical expenses category, and

$$
v_{t}=\rho v_{t-1}+\varepsilon_{t}, \quad \varepsilon_{t} \sim N\left(0, \sigma_{\varepsilon}^{2}\right)
$$

\footnotetext{
${ }^{13}$ The results do not significantly change if we change the cutoff point to 6 or 12 months.

${ }^{14}$ More details on this are available in Pashchenko and Porapakkarm (2012).
} 


$$
\xi_{t} \sim N\left(0, \sigma_{\xi}^{2}\right)
$$

For the persistent shock $v_{t}$ we set $\rho$ to 0.98 and $\sigma_{\varepsilon}^{2}$ to 0.018 following the incomplete market literature (Storesletten et al (2004); Hubbard et al (1994); Erosa et al (2011); French $(2005))$. We set the variance of the transitory shock $\left(\sigma_{\xi}^{2}\right)$ to 0.1 which is in the range estimated by Erosa et al (2011). In our computation we discretize the stochastic shocks $v_{t}$ and $\xi_{t}$ using the method in Floden (2008). ${ }^{15}$ To construct the distribution of newborn individuals, we draw $v_{1}$ in equation $(20)$ from $N(0,0.124)$ distribution following Heathcote et al. (2010).

To identify the deterministic part of productivity $\lambda_{t}^{e, x}$ we need to take into account that in the data we only observe labor income of workers and we do not know the potential income of non-workers. To address this problem we use the method developed by French (2005) and described in detail in Pashchenko and Porapakkarm (2012). We start by estimating the labor income profiles of workers based on the MEPS dataset. ${ }^{16}$ Then we estimate $\lambda_{t}^{e, x}$ in equation (19) inside the model in order to reproduce the average labor income profile of workers as in the data. The advantage of this approach is that we can reconstruct the productivity $z_{t}^{e, x}$ of individuals whom we do not observe working in the data. Figure (1) plots the labor income profiles of workers observed in the data and simulated by the model, and compares them with the average potential labor income computed for everyone in the model. Our estimates show that the average labor income of workers is higher than the average labor income that includes potential income of nonworkers because people with low productivity tend to drop out from the employment pool. In other words, if we do not use the correction described above we would overestimate the labor income for non-participating individuals and this bias is especially strong in the case of unhealthy people and people at pre-retirement age. We also find that unhealthy people are inherently less productive. The drop in productivity due to bad health depends on age but it can be as high as $22 \%$ for high-school dropouts and as high as $15 \%$ for people with at least a high-school degree.

\section{Baseline model performance}

Figure (2) compares the employment profiles observed in the data with the ones generated by the model. The model closely tracks the employment profiles for each

\footnotetext{
${ }^{15}$ We use 9 grid points for $v_{t}$ and 2 grid points for $\xi_{t}$. The grid of $v_{t}$ is expanding to capture the increasing cross-sectional variance. Our discretized process for $v_{t}$ generates the autocorrelation of 0.98 and 0.016 for its innovation variance.

${ }^{16}$ Household labor income is defined as the sum of wages (variable WAGEP) and $75 \%$ of the income from business (variable BUSNP). This definition is the same as the one used in the Panel Study of Income Dynamics Dataset (PSID), which has been commonly used for income calibration in the macroeconomic literature.
} 

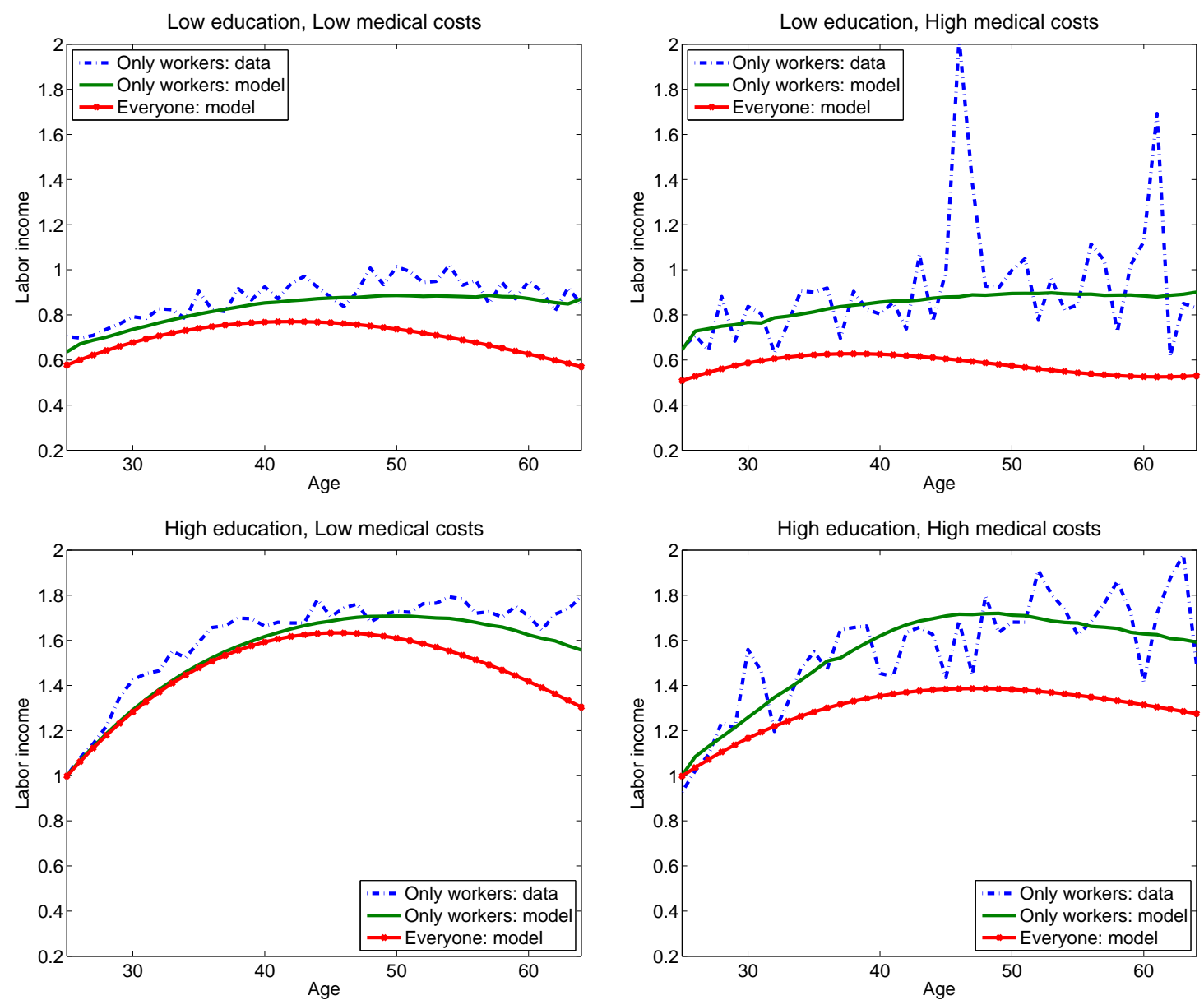

Figure 1: Average labor income of workers (data and model) and of everyone (model). The later profile takes into account the unobserved productivity of those people who do not work.

educational and health group though it slightly overestimates employment rate of the youngest group because we abstract from labor market frictions.

Table 3 compares the aggregate health insurance statistics generated by the model with the ones observed in the data. The model was calibrated to match the data on ESHI take-up rates and individual insurance rates. However, the model also produces numbers on the fractions of uninsured and publicly insured close to the data. The last four columns of Table 3 show insurance statistics by educational groups. Our model does not target any of these statistics, but it still fares well along these dimensions.

The top panel of Figure (3) plots the percentages of the uninsured and those publicly insured in the model and in the data. For both educational groups, the model can capture the corresponding empirical profiles. There is an overprediction in the number of publicly insured for people of preretirement age due to our simplified Medicaid eligibility criteria. The bottom panel of Figure (3) compares the life-cycle profiles of the fraction of people with private insurance for different educational groups in the model and in the data. The 

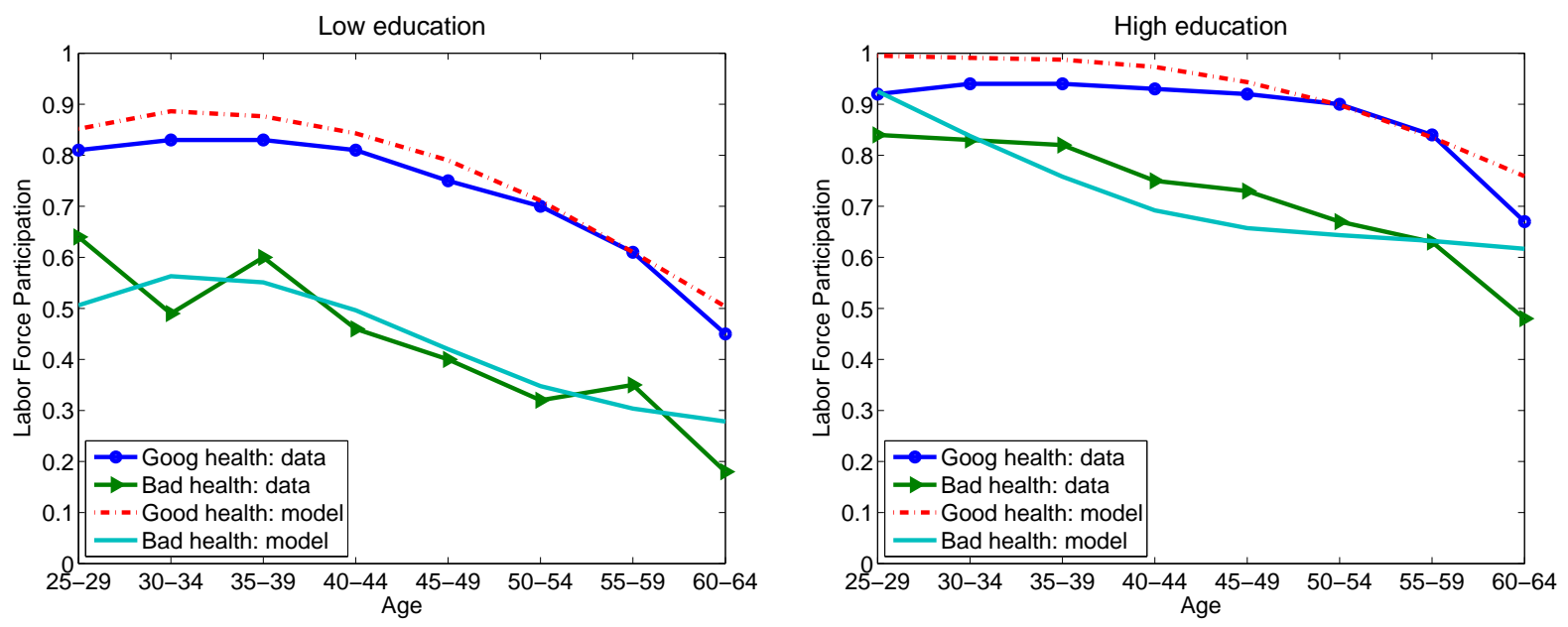

Figure 2: Employment profiles for people with low education (left panel) and high education (right panel): data vs. model

\begin{tabular}{|c|cc|cc|cc|}
\hline \hline & \multicolumn{2}{|c|}{ All } & Low education & \multicolumn{2}{c|}{ High education } \\
\cline { 2 - 7 } & Data & Model & Data & Model & Data & Model \\
\hline Insured by ESHI (\%) & 63.0 & 64.4 & 33.3 & 29.1 & 68.5 & 70.6 \\
Individually insured (\%) & 7.6 & 7.3 & 5.5 & 3.8 & 8.0 & 8.0 \\
Uninsured (\%) & 20.2 & 19.7 & 39.5 & 43.2 & 16.6 & 15.6 \\
Publicly insured (\%) & 9.2 & 8.6 & 21.7 & 23.8 & 6.9 & 5.9 \\
ESHI take-up rate (\%) & 94.3 & 94.2 & 85.9 & 81.6 & 93.9 & 95.3 \\
Offer rate (\%) & 67.6 & 68.3 & 38.8 & 35.7 & 72.9 & 74.1 \\
Group premium/avg.income (\%) & 7.0 & 6.7 & - & - & - & - \\
\hline \hline
\end{tabular}

Table 3: Insurance statistics: data vs. model

model reproduces the general life-cycle pattern and differences in educational group in insurance rates. However, for low educated people it underestimates the fraction of people with ESHI among the older group which happens because we overestimate the fraction of the publicly insured for this age category. The model also tends to underpredict the fraction of people with individual insurance among young low-educated people because we assume only one choice of plan in the individual insurance market.

Our model also produces a reasonable number of poor people: the fraction of people (including retirees) with assets less than $\$ 1,000$ is $10.9 \%$. In the Survey of Consumer Finance (SCF) this number is $11.1 \%$ in 2004 (Kennickell, 2006). 

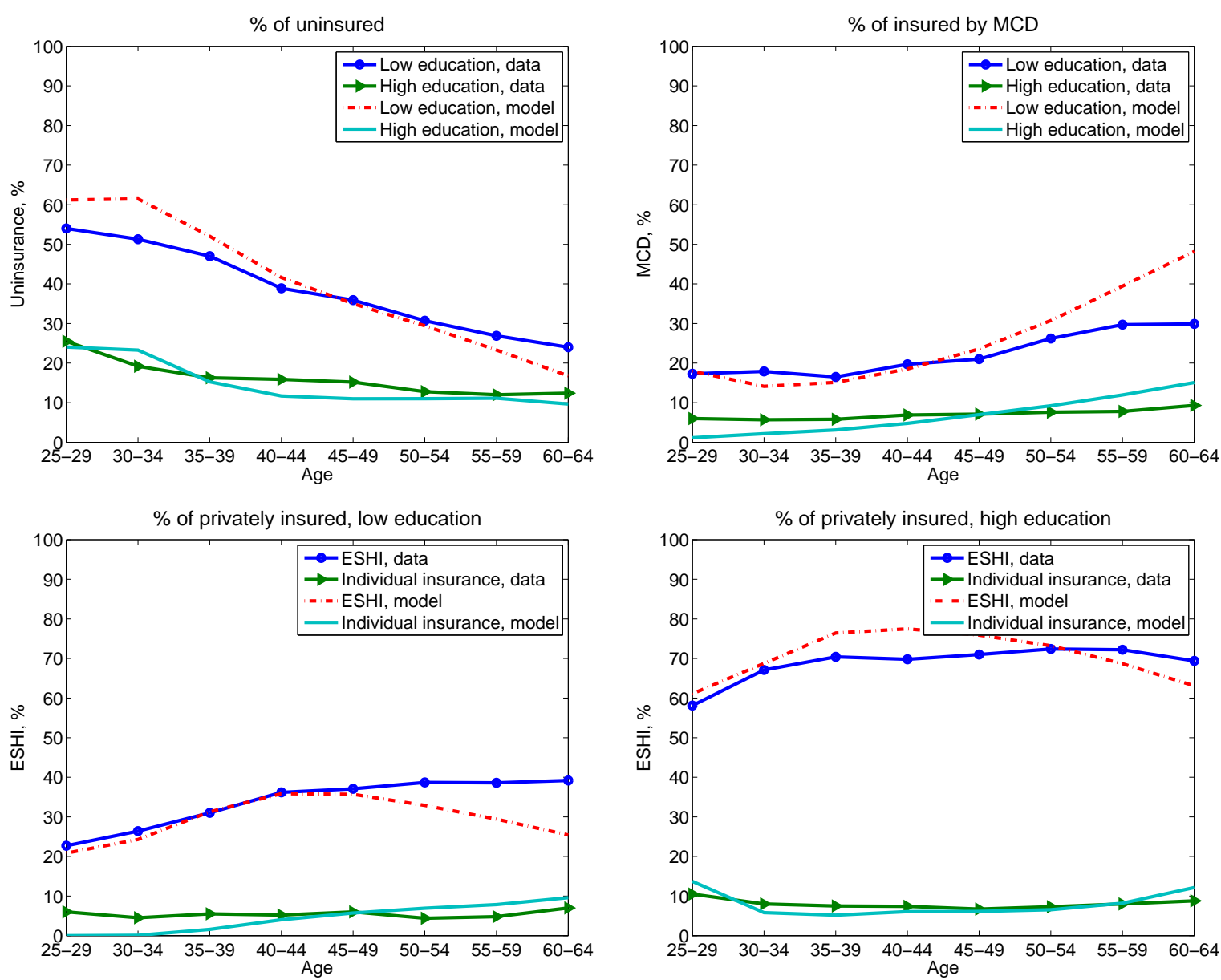

Figure 3: Percent of uninsured and publicly insured (top panel) and privately insured (bottom panel) data vs. model

\section{Results}

This section is organized as follows. We start by illustrating the role of the currently existing tax subsidies in preventing the ESHI pool from unraveling. Next, we construct the following policy experiment: instead of the current tax exclusion we introduce an individually-adjusted direct subsidy that i) only goes to individuals who will leave the pool if not subsidized, ii) makes such individuals slightly better off from staying in the pool. Our main goal in constructing this experiment is to understand how this subsidy scheme will look like and what will be total spending to finance it. Next, building on these results we consider a policy that reforms the current tax subsidy in order to roughly mimic the allocation of transfers obtained with the individually-adjusted direct subsidies. We compare how the effects of this tax reform will differ after the implementation of the ACA. Finally, we discuss the welfare effects of this tax subsidy reform. 


\subsection{The role of the tax exclusion in keeping the ESHI pool together}

To understand the role of the currently existing tax subsidies in keeping the ESHI pool together we consider an experiment where ESHI premiums cannot be excluded from taxable income. In this case the total taxable income in equation (9) is determined in the following way:

$$
y_{t}^{N D}=r k_{t}+\widetilde{w} z_{t}^{e, x} l_{t}+\psi p \mathbf{1}_{\left\{i_{H}^{\prime}=G\right\}}-\max \left(0, x_{t}\left(1-q\left(x_{t}, i_{t}\right)\right)-0.075\left(\widetilde{w} z_{t}^{e, x} l_{t}+r k_{t}\right)\right)
$$

And the total tax is now determined as follows:

$\operatorname{Tax}^{N D}=\mathcal{T}\left(y_{t}^{N D}\right)+\tau_{y} y_{t}^{N D}+\tau_{m e d}\left(\widetilde{w} z_{t}^{e, x} l_{t}+\psi p \mathbf{1}_{\left\{i_{H}^{\prime}=G\right\}}\right)+\tau_{s s} \min \left(\widetilde{w} z_{t}^{e, x} l_{t}+\psi p \mathbf{1}_{\left\{i_{H}^{\prime}=G\right\}}, \bar{y}_{s s}\right)$

Note that comparing to equations (8) and (9) both employee's and employer's contributions become a part of the taxable income.

Table 4: The effect of differentiated tax subsidy: the ESHI take-up rates and total spending on subsidies

\begin{tabular}{|l|c|c|c|c|c|c|}
\hline & \multicolumn{2}{|c|}{ ESI take-up $(\%)$} & Subsidy & Tax rate & Agg K \\
& All & LE & HE & $(\%$ BS $)$ & $\tau_{y}(\%)$ & $(\%$ BS $)$ \\
\hline Baseline & 94.2 & 81.6 & 95.3 & 100.0 & 6.86 & 100.0 \\
1. No tax subsidy & 6.3 & 4.0 & 6.5 & 0.0 & 6.07 & 103.8 \\
2. Differentiated subs. & 85.4 & 53.3 & 88.1 & 26.4 & 5.93 & 100.4 \\
3. Differentiated subs.+age-adjusted CR & 90.0 & 62.6 & 92.4 & 16.2 & 5.66 & 102.1 \\
\hline
\end{tabular}

\begin{tabular}{|l|c|c|c|c|c|c|}
\hline & \multicolumn{3}{|c|}{ Employment (\%) } & \multicolumn{3}{|c|}{ Insurance (\%) } \\
& All & LE & HE & Unins & Indiv & MCD \\
\hline Baseline & 89.7 & 75.6 & 92.2 & 19.7 & 7.3 & 8.6 \\
1. No tax subsidy & 86.9 & 74.7 & 89.2 & 62.4 & 22.7 & 10.8 \\
2. Differentiated subs. & 88.8 & 75.3 & 91.2 & 26.3 & 7.0 & 9.2 \\
3. Differentiated subs.+age-adjusted CR & 88.6 & 75.4 & 90.9 & 23.4 & 7.1 & 9.2 \\
\hline
\end{tabular}

Table 5: The effect of differentiated tax subsidy: employment and insurance

The first row of Table 4 shows that the elimination of the tax exclusion results in almost complete unraveling in the employer-based market: the take-up rate drops from $94.2 \%$ to $6.3 \%$. At the same time, the uninsurance rate increases to $62.4 \%$ (row number 1 of Table 4). This suggests that tax subsidies is an important mechanism to maintain a good risk-sharing inside the employer-based pool. ${ }^{17}$

\footnotetext{
${ }^{17}$ Jeske in Kitao (2009) find that the elimination of the tax exclusion results in a less dramatic unraveling of the ESHI market. This difference in our results is due to the fact that they abstract from age dimension which substantially reduces the amount of cross-subsidization in the ESHI pool. As will be shown in the next section, the removal of cross-subsidization along the dimension of age increases
} 
Figure (4) illustrates the intuition behind this result. This figure compares the riskadjusted premiums in the individual market with out-of-pocket costs of ESHI in the baseline economy. The out-of-pocket costs of ESHI $\left(p^{O O P}\right)$ are defined in the following way:

$$
p^{O O P}=p(1-\psi)+\Delta T a x
$$

where $p(1-\psi)$ is the employee's contribution and $\Delta$ Tax is the difference in tax payments resulting from the purchase of ESHI, $\Delta$ Tax $=\operatorname{Tax}^{i_{H}^{\prime}=G}-\operatorname{Tax}_{i_{H}^{\prime} \neq G}$. If the ESHI premium can be excluded from taxable income, an individual saves on taxes by buying employerbased insurance, i.e. $\Delta \operatorname{Tax}<0$. If the tax exclusion is removed, an individual buying ESHI has to pay additional taxes on his premium, i.e. $\Delta \operatorname{Tax}^{N D}>0$.

The difference in the ESHI costs with and without tax exclusion is enough to trigger the adverse selection spiral. As shown in Figure (4), for young people in the two lowest medical expenses grids the out-of-pocket costs of ESHI exceed their risk-adjusted prices in the individual market after the tax subsidy is removed. ${ }^{18}$ These people initiate the unraveling by dropping out of the employer-based market and this leads to an increase in the ESHI premium and further unraveling of the pool.

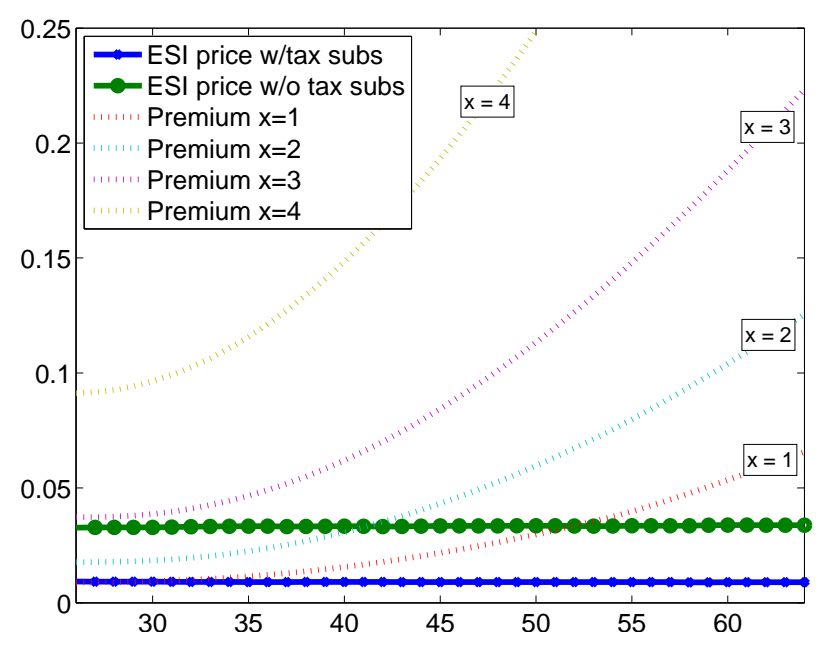

Figure 4: Individual premiums vs. out-of-pocket group premium with and without tax exclusion

Another observation from Figure (4) is that for older people and people in the high medical costs grids the out-of-pocket costs of ESHI are substantially lower than their risk-adjusted individual premiums even when the tax exclusion is removed. These people enjoy large implicit cross-subsidies from people with low expected medical costs and they have incentives to buy ESHI even without tax subsidies. Figure (5) illustrates this point

incentives to participate in the ESHI pool for young and healthy people.

${ }^{18}$ When constructing Figure (4) the premium used to compute out-of-pocket costs of ESHI after the removal of the tax exclusion is fixed as in the baseline. After the unraveling starts this price will substantially increase. 
further by showing the markup that individuals with different expected medical costs face in the ESHI pool. The markup is measured as a percentage difference between the risk-adjusted and the pooled prices. ${ }^{19}$ The negative markup means that an individual is overpaying comparing to his risk-adjusted price, thus cross-subsidizing other participants in the pool, while the positive markup means an individual is cross-subsidized. Community rating puts a big strain on healthy people younger than 35 years old - their markup can be as large as $-250 \%$. In contrast, people above age 60 with bad health enjoy almost $100 \%$ discount to their risk-adjusted price when they participate in the group market. We explore the possibilities of designing subsidies that take this cross-subsidization into account in the next section.
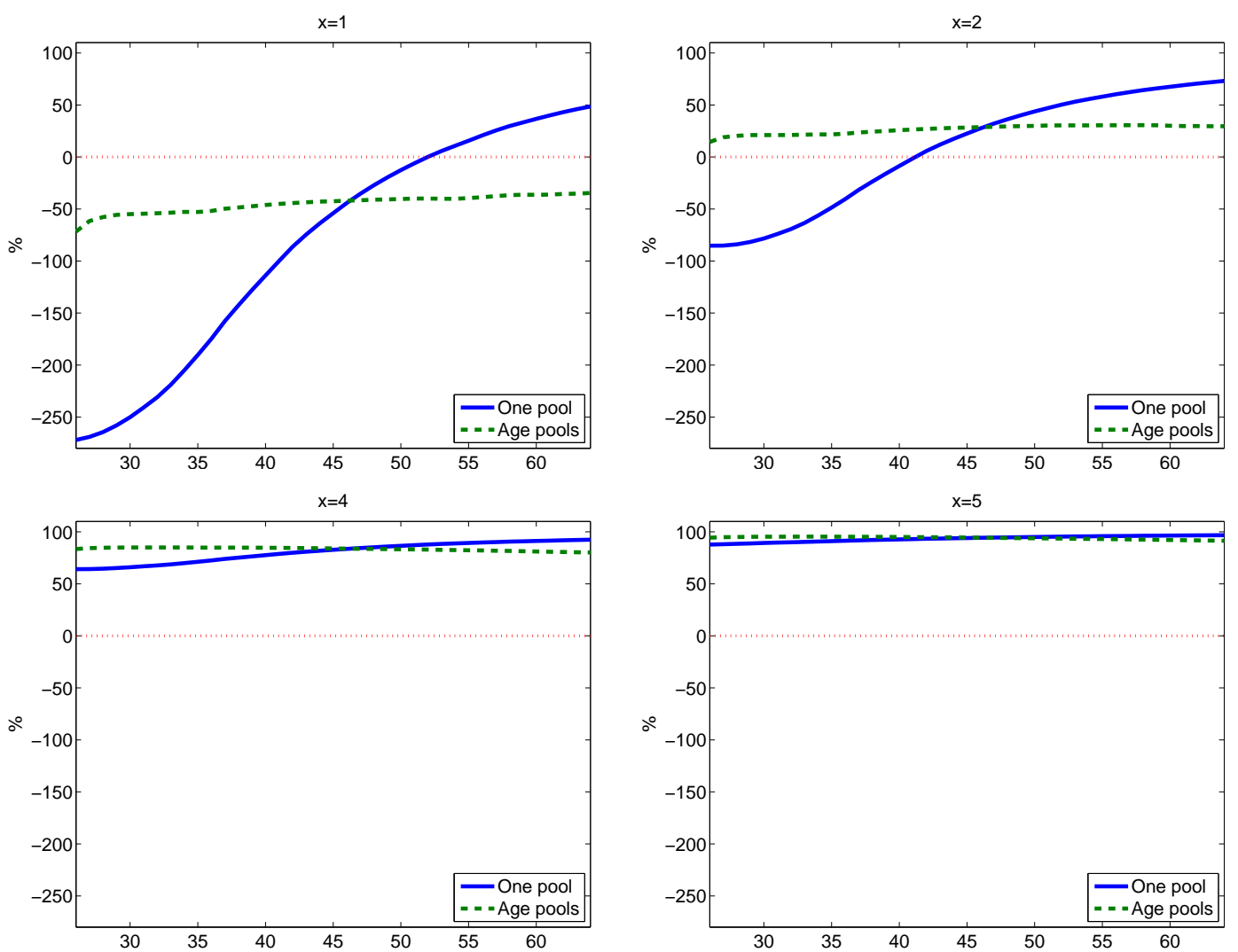

Figure 5: Markup for people in different medical expense grids in case of a community rated ESHI market. The solid lines are the markup in a single pool in the baseline economy. The dashed lines are the markup in case ESHI premiums are age-adjusted.

\subsection{The effect of direct differentiated subsidies}

In this section we consider a flexible subsidy scheme that only targets people with weak incentives to participate in the ESHI pool. More specifically, we remove the tax exclusion of the ESHI premium and instead introduce a direct differentiated subsidy. This

\footnotetext{
${ }^{19}$ For the left panel of Figure (5) the pooled ESHI price is as in the baseline economy.
} 
subsidy compensates people with low expected medical costs more because in the pool they cross-subsidize people with high expected medical costs. The subsidy is determined in the following way:

$$
\text { subs }_{i}=\max \left\{0, p^{O O P}-\frac{E M\left(x_{t}, t\right)}{1+r}\right\}
$$

An individual with positive subsidy receives a difference between his actuarially fair price $\frac{E M\left(x_{t}, t\right)}{1+r}$ and his out-of-pocket costs of ESHI $p^{O O P}$. Note that only individuals who are likely to leave the pool if not subsidized get a positive subsidy. This subsidy makes such an individual slightly better off from buying the group rather than individual insurance since in the individual insurance market he has to pay a markup due to administrative costs on top of his actuarially fair price.

The results of the implementation of this subsidy scheme are presented in the second row of Table 4. The differentiation of the subsidy results in a small decrease in the takeup rate: from $94.2 \%$ to $85.4 \%{ }^{20}$ At the same time, the total spending on these direct subsidies represents only $26.4 \%$ of the tax expenditures used to keep the ESHI pool together in the baseline economy. ${ }^{21}$ In other words, removing the subsidy for those who already get cross-subsidized inside the pool results in almost the same level of risk-sharing at one fourth of the costs.

The left panel of Figure (6) illustrates how the size of the subsidy varies by age and health. Not surprisingly, people who get the highest subsidies are those younger than 35 years old and in the lowest medical costs grid. These people are the most disadvantageous group in the employer-based pool as was shown in Figure (5), and thus they have to get the highest compensation. It is also important to point out that people above age 55 and people in medical costs grids 4 and 5 never get subsidized but they stay in the pool suggesting inefficiency of uniform subsidization.

The left panel of Figure (6) illustrates that the most 'costly' participants in the community-rated pool are young healthy people: they have to be subsidized a lot in order to stay in the pool. This happens because in case of uniform community rating all people face the same premium. Since expected medical costs increase steeply with age this implies a large cross-subsidization from the young to the old. The whole system of transfers inside this pool looks as follows: the young cross-subsidize the old and the government directly subsidizes the young in order for them to stay in the pool. In

\footnotetext{
${ }^{20}$ Note that not all individuals are willing to buy health insurance even at actuarially fair prices. This happens because health insurance covers only part of medical costs. At the same time, uninsured individuals can rely on government means-tested transfers provided through the consumption minimum floor and the Medically Needy program.

${ }^{21}$ In the baseline economy the costs to keep the pool together represent the tax revenue forgone because of the tax exclusion. It can be computed as follows: $\int\left[\operatorname{Tax}^{N D}(\boldsymbol{s})-\operatorname{Tax}(\boldsymbol{s})\right] \Gamma(\boldsymbol{s})$. In the economy with the differentiated subsidy scheme these costs represent the direct subsidy spending.
} 

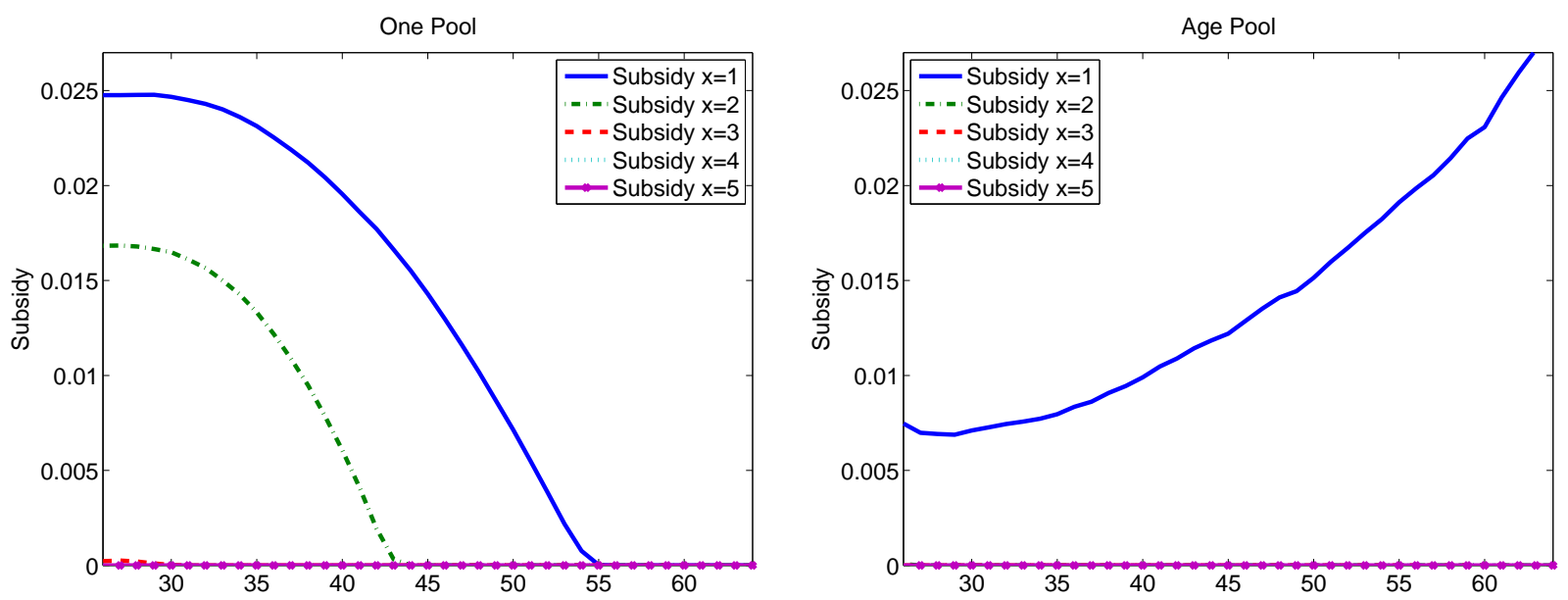

Figure 6: Differentiated subsidies in case of one pool (left panel) and age pool (right panel). On the left panel the lines for medical cost grids 3 to 5 lie on the horizon axis. On the right panel the lines for medical cost grids 2 to 5 lie on the horizon axis.

contrast, if community rating in the ESHI market is age-adjusted, there will be no crosssubsidization from the young to the old but only from the healthy to the unhealthy. Since the difference in expected medical costs between healthy and unhealthy individuals of the same age is smaller than this difference between the healthy young and the unhealthy old, age-adjusted pools imply less cross-subsidization and thus less direct subsidies are needed to maintain high participation rate in the pool.

As a next experiment we consider how the differentiated subsidy scheme will look like if we introduce age-adjusted community rating in the group market, i.e. we allow the ESHI premium to depend on age (but not on the current medical costs) of an individual. Thus the ESHI premium in Eq (16) is replaced by age-dependent premium below:

$$
p(\hat{t})=(1+r)^{-1} \gamma \frac{\left(\int_{\mathbf{t}=\widehat{t}} \mathbf{1}_{\left\{i_{H}^{\prime}(\mathbf{s})=G\right\}} E M\left(x_{t}, t\right) \Gamma(s)\right)}{\int_{\mathbf{t}=\widehat{t}} \mathbf{1}_{\left\{i_{H}^{\prime}(\mathbf{s})=G\right\}} \Gamma(\boldsymbol{s})} .
$$

The third row Table 4 shows that the implementation of the differentiated subsidy scheme together with age-adjusting community rating results in the take-up rate equal to $90.0 \%$ (comparing to $94.2 \%$ in the baseline). Importantly, the total spending on subsidies now represent only $16.2 \%$ of the tax expenditures in the baseline economy. In other words, when the cross-subsidization along the dimension of age is removed it is much cheaper to maintain a good risk-sharing in the employer-based market. Figure (5) shows that the markup that young people face in case of age-adjusted community rating is much lower than in case of uniform community rating. Because of this, as the right panel of Figure (6) illustrates, now only people in the lowest medical costs grid get a direct subsidy. The amount of this subsidy is increasing with age because the expected 
medical expenses of people in the first grid of medical expenses increase much slower with age then the average medical expenses. As they age, people who stay in the lowest medical costs grid need a higher compensation in order to agree to pool their risks with people in higher medical costs grids.

\subsection{Reforming the tax exclusion of ESHI premiums}

The previous section illustrates that we can use direct differentiated subsidies to maintain a good risk-sharing in the employer-based pool at relatively low costs. In this section we investigate if the currently existing tax subsidy can be modified in order to achieve a similar outcome. The tax exclusion is a less flexible instrument than a direct subsidy. However, one result from the previous section that can be applied even in case of the tax subsidy is that only people with weak incentives to participate in the ESHI pool should be subsidized. To mimic this result we consider a policy that instead of providing tax exclusion to everyone only targets a group of people who would get the direct subsidy in the experiment described in the previous section. At the same time we withdraw the tax exclusion from people who would not get any direct subsidy. ${ }^{22}$

\begin{tabular}{|l|c|c|c|c|c|c|}
\hline & \multicolumn{2}{|c|}{ ESI take-up $(\%)$} & Subsidy & Tax rate & Agg K \\
& All & LE & HE & $(\%$ BS $)$ & $\tau_{y}(\%)$ & $(\% \mathrm{BS})$ \\
\hline Baseline & 94.2 & 81.6 & 95.3 & 100.0 & 6.86 & 100.0 \\
1. No tax subsidy & 6.3 & 4.0 & 6.5 & 0.0 & 6.07 & 103.8 \\
Tax subsidy only to a certain group: & & & & & & \\
2. $(\mathrm{x}=1$ and age $\leq 55)$ or $(\mathrm{x}=2$ and age $\leq 43)$ & 92.5 & 70.8 & 94.3 & 43.9 & 6.15 & 100.6 \\
3. x=1+age-adj CR & 97.1 & 81.3 & 98.5 & 34.6 & 5.89 & 101.5 \\
\hline
\end{tabular}

Table 6: The effects of tax subsidy reforms

The left panel of Figure (6) illustrates that in the direct differentiated subsidy scheme two groups get subsidized: people in the lowest medical expense grid and younger than 55 years old, and people in the second lowest medical expense grid and younger than 43 years old. To imitate these results we consider a policy where only these two groups are allowed to keep the tax exclusion. The second row of Table 6 illustrate the effect of this reform (Table 9 in Appendix A illustrates the effect on the employment and insurance status). Allowing young and healthy people to keep the tax exclusion prevents the ESHI pool from unraveling: the take-up rate is $92.5 \%$ which is only $2 \%$ lower than in the baseline. At the same time, the costs of the tax subsidy go down more than twice comparing to the baseline level (43.9\%). Note that even though these savings are considerable, they

\footnotetext{
${ }^{22}$ In this experiment the taxable income and tax payments are determined according to equations (8) and (9) for the group that is allowed to keep the tax exclusion and according to equations (21) and (22) for the rest of the ESHI pool participants.
} 
are not as high as in the case of direct differentiated subsidies. This happens because the size of the tax subsidy (unlike the size of the direct subsidy) cannot be adjusted for individual risk. Figure (6) shows that the size of the direct subsidy is steeply decreasing with age and this represents a significant source of savings because older people need less incentives in order to join the pool.

The results of the previous section illustrate that high participation in the ESHI pool can be achieved at significantly smaller costs if community rating in the ESHI market is age-adjusted. In the next experiment we introduce age-adjusted premiums in the ESHI market. At the same time, we allow only people in the lowest medical expense grid to keep the tax exclusion since only this group receives direct subsidies in this case as shown in the right panel of Figure (6). Row numbered 3 of Table 6 shows that this reform results in the take-up rate that is even higher than the baseline level (97.1\%). At the same time, the costs of these tax subsidies represent around one third (34.6\%) of the baseline level.

The important result from this section is that the reform that achieves good risksharing in the ESHI market at very low costs consists of two steps: i) the existing tax subsidy should be targeted only to low-risk people, and ii) ESHI premiums should be age-adjusted.

\subsection{Elimination of the tax exclusion after the ACA}

This section considers the effects of the tax exclusion reform after the implementation of the ACA. The main changes that the ACA introduces to the economy are as follows. First, there will be age-adjusted community rating in the individual market meaning that premiums can only depend on age but not on health conditions of individuals. Second, low-income people will get subsidies to buy health insurance in the individual market. The subsidy will be determined based on a sliding scale. People with income below $133 \%$ of FPL will get the highest subsidy while people with income above $400 \%$ of FPL will not get any subsidy. Third, the income eligibility threshold for the general Medicaid program $\left(y^{\text {cat }}\right)$ will increase to $133 \%$ of FPL. Fourth, people who stay uninsured will have to pay penalties. Appendix B describes in detail how the ACA changes the baseline model.

\begin{tabular}{|l|c|c|c|c|c|c|}
\hline & \multicolumn{2}{|c|}{ ESI take-up $(\%)$} & Subsidy & Tax rate & Agg K \\
& All & LE & HE & $(\%$ BS $)$ & $\tau_{y}(\%)$ & $(\%$ BS $)$ \\
\hline Economy after the reform & 94.2 & 75.6 & 95.9 & 100.0 & 6.86 & 100 \\
1. No tax subsidy & 52.6 & 31.6 & 54.4 & 0.0 & 5.70 & 99.6 \\
2. No tax subsidy, no penalties & 5.3 & 3.8 & 5.4 & 0.0 & 6.44 & 104.2 \\
Tax subsidy only to a certain group: & & & & & & \\
3. $(\mathrm{x}=1$ and age $\leq 55)$ or $(\mathrm{x}=2$ and age $\leq 43)$ & 93.6 & 72.5 & 95.5 & 47.0 & 6.32 & 100.1 \\
\hline 4. $\mathrm{x}=1$ and age-adjusted CR & 94.4 & 74.3 & 96.2 & 35.8 & 6.22 & 101.5 \\
\hline
\end{tabular}

Table 7: The effect of the partial removal of the tax exclusion after the ACA 
The first row of Table 7 reports the ESHI take-up rate for the new long-run steadystate equilibrium after the implementation of the ACA. Table 10 in Appendix A reports the employment and insurance statistics. ${ }^{23}$ We will use this economy as a reference when comparing the effect of the tax subsidy reforms in this section. When implementing the ACA we assume that all additional government spending needed to pay for subsidies and expanded Medicaid are financed by increasing the progressive income tax and this increase disproportionably falls on high-income people. This is done to reflect that the important source of the ACA financing comes from levying higher taxes on the rich. More specifically, we adjust the parameter $a_{0}$ of the tax function to balance the government budget during the implementation of the ACA. As a result, this parameter increases from 0.258 (baseline level) to 0.285 . The resulting average tax rate for a person with average income increases by 1.2 percentage point.

The row numbered 1 of Table 7 shows the effect of the complete elimination of the tax exclusion after the reform (Table 10 in Appendix A reports corresponding changes in the employment and insurance). In contrast to the economy before the ACA, this reform does not lead to the full unraveling of the employer-based pool: the take-up rate decreases only to $52.6 \%$. Row 2 of Table 7 shows that this high take-up rate is due to the penalty for the uninsured imposed by the ACA: if the penalty is removed the elimination of the tax subsidy results in the take-up rate equal to $5.3 \%$.

Row 3 of Table 7 shows the effects of the reform that allows only two groups to keep the tax exclusion: people in the lowest medical expense grid and younger than 55 years old, and people in the second lowest medical expense grid and younger than 43 years old. This reform results in slightly lower take-up rate (93.6\% comparing to $94.2 \%$ ) but the tax expenditures constitute less than half $(47 \%)$ of the post-ACA baseline level.

Row 4 of Table 7 shows the effects of targeting tax exclusion only at people at the lowest grid of medical expenses combined with age-adjustment of premiums in the ESHI market. As before, this policy achieves good risk-pooling with the least costs: the take-up rate is the same as in the post-ACA baseline (around 94\%) while the tax expenditures constitute $35.8 \%$ of the post-ACA baseline level.

\subsection{Welfare effects}

This section evaluates welfare effects of the tax subsidy reform that achieves good riskpooling at the lowest costs and compares them with the welfare effects of the complete elimination of the tax exclusion. Rows 1 and 4 of Table 8 show that the complete elimination of the tax subsidy results in substantial ex-ante welfare losses both in the pre-ACA and post-ACA economies: consumption equivalent variation $(\mathrm{CEV})$ is equal to

\footnotetext{
${ }^{23}$ For the full analysis of the effects of the ACA on the economy see Pashchenko and Porapakkarm (2012).
} 
$-0.46 \%$ of the annual consumption in the former case and $-0.36 \%$ in the latter. There is heterogeneity in welfare effects by educational group: people with high education lose around $1 \%$ of the annual consumption while people with low education gain. Many people in the latter group do not have access to the employer-based market so they do not suffer from its unraveling but enjoy a lower tax rate which results from lower government tax expenditures.

\begin{tabular}{|c|c|c|c|c|c|c|}
\hline & \multicolumn{3}{|c|}{$\mathrm{CEV}(\%)$} & \multirow{2}{*}{$\begin{array}{l}\text { Costs } \\
(\% \mathrm{BS})\end{array}$} & \multirow{2}{*}{$\begin{array}{c}\text { Tax rate } \\
\tau_{y}(\%)\end{array}$} & \multirow{2}{*}{$\begin{array}{c}\text { ESHI } \\
\text { Take-up }\end{array}$} \\
\hline & All & LE & $\mathrm{HE}$ & & & \\
\hline Before ACA & & & & & & \\
\hline Baseline & - & - & - & 100.0 & 6.86 & 94.2 \\
\hline $\begin{array}{l}\text { 1.No tax subsidy } \\
\text { Tax subsidy only to a certain group: }\end{array}$ & -0.46 & 0.27 & -1.08 & 0.0 & 6.07 & 6.03 \\
\hline 2. $\mathrm{x}=1+$ age-adj $\mathrm{CR}$ & 0.18 & 0.41 & -0.01 & 34.6 & 5.89 & 97.1 \\
\hline 3. $\mathrm{x}=1 \&$ income $<2 * \mathrm{FPL}+$ age-adj $\mathrm{CR}$ & 0.61 & 0.79 & 0.46 & 42.4 & 5.89 & 98.5 \\
\hline After ACA & & & & & & \\
\hline After-ACA baseline & - & - & - & 100.0 & 6.86 & 94.2 \\
\hline $\begin{array}{l}\text { 4. No tax subsidy } \\
\text { Tax subsidy only to a certain group: }\end{array}$ & -0.36 & 0.41 & -0.98 & 0.0 & 5.70 & 52.6 \\
\hline 5. $\mathrm{x}=1+$ age-adj $\mathrm{CR}$ & -0.15 & 0.16 & -0.40 & 35.8 & 6.22 & 94.4 \\
\hline 6. $\mathrm{x}=1 \&$ income $<2 * \mathrm{FPL}+$ age-adj $\mathrm{CR}$ & 0.13 & 0.42 & -0.11 & 42.0 & 6.23 & 94.7 \\
\hline
\end{tabular}

Table 8: Ex-ante welfare of newborns for different policy experiments

Rows 2 and 5 of Table 8 show welfare effects of the policy that combines age-adjusted community rating in the group market with the removal of the tax exclusion from all groups except those in the lowest medical costs grid before and after the ACA. Before the ACA this tax subsidy reform brings positive welfare gains (0.18\%) while after the ACA the welfare effects become negative $(-0.15 \%)$. In general, this policy withdraws subsidies from all people whose medical expenses are not in the bottom $30 \%$ of the medical expense distribution regardless of their income. However, even though the average income of the ESHI pool participants is relatively high, there is a substantial income heterogeneity. The loss of tax subsidies by low-income people with high medical costs negatively affects welfare. At the same time, the introduction of age-adjusted premiums in the ESHI market positively affects welfare because it results in the decrease in ESHI premiums for young people many of whom have low income. ${ }^{24}$ Before the implementation of the ACA the positive welfare effect from age-adjusted ESHI premiums dominates the negative welfare effect from withdrawing tax subsidies from low-income people. After the ACA the opposite is true because after the reform the tax rate is higher and thus the size of the tax subsidy is higher as well. Withdrawing this subsidy from low income people

\footnotetext{
${ }^{24}$ Just introducing the age-adjusted community rating in the ESHI market in the baseline economy results in ex-ante welfare gains equivalent to $0.27 \%$ of the annual consumption.
} 
have more noticeable welfare effect that cannot be fully offset by the age-adjustment of premiums in the group market.

To improve welfare outcomes we extend the tax subsidy to people with income below $200 \%$ of FPL. Rows 3 and 6 of Table 8 report welfare effects of this modified policy before and after the ACA. Before the ACA the resulting welfare gains increase to $0.61 \%$ and after the ACA - to $0.13 \%$. At the same time, tax expenditures do not increase much: before the ACA the tax expenditures increase from $34.6 \%$ to $42.4 \%$ of the baseline level and after the ACA - from $35.8 \%$ to $42.0 \%$ of the level of the post-ACA baseline. ${ }^{25}$ In other words, both before and after the ACA the spending on tax subsidies can be decreased by almost $60 \%$ without the unraveling of the employer-based market and without decreasing the welfare. To achieve these results it is important to target tax subsidies to people with low expected medical expenses and people with low income, and to allow for age-adjustment of premiums in the group market.

\section{Conclusion}

In this paper we study the possible reform of the currently existing tax subsidy for people buying employer-based health insurance. We find that even though the complete elimination of the tax subsidy leads to the unraveling of the employer-based market there is a room for substantial savings by targeting the tax subsidy. We show that good risk-poling in the employer-based market can be achieved at lower costs if the subsidy scheme takes into account the fact that people have different incentives to participate in the employer-based pool. In the employer-based market high-risk people get implicit cross-subsidies from low-risk people and thus it is relatively easy to motivate them to join the pool. In contrast, for low-risk people the employer-based insurance pool is less attractive. Based on this intuition we illustrate how would a subsidy schedule look like if each individual receives direct subsidy that can be tailored to his expected medical expenses. Building on these results we propose a way to reform the existing tax exclusion. We show that this reform results in the same level of risk-pooling in the group market as in the baseline but at one third of the costs. In order to achieve these results only people in the bottom $30 \%$ of medical expenses distribution should be allowed to keep the tax exclusion. In addition, the premiums in the group market should become age-adjusted in order to remove cross-subsidies from the young to the old and thus to make the ESHI pool more attractive for the young. In order to improve welfare outcome of this policy

\footnotetext{
${ }^{25}$ Note, that before the ACA the extension of the tax exclusion to low-income people does not affect the tax rate because individuals newly eligible for the tax subsidy previously didn't participate in the ESHI market and thus didn't pay taxes on their premiums. In contrast, after the ACA the extension of the tax exclusion to low-income people changes the tax rate because newly eligible for tax subsidy individuals were previously buying ESHI (the take-up rate does not change).
} 
it is important to extend the tax exclusion to people with income below $200 \%$ of FPL which increase the tax expenditure to around $40 \%$ of the baseline level.

\section{A The effect of tax exclusion reform on employment and insurance statistics}

Table 9 shows the change in the insurance and employment behavior as a result of the tax subsidy reform before the ACA and Table 10 - after the ACA.

Table 9: The effects of tax subsidy reform before the ACA

\begin{tabular}{|l|c|c|c|c|c|c|}
\hline & \multicolumn{3}{|c|}{ Employment (\%) } & \multicolumn{4}{|c|}{ Insurance (\%) } \\
& All & LE & HE & Unins & Indiv & MCD \\
\hline Baseline & 89.7 & 75.6 & 92.2 & 19.7 & 7.3 & 8.6 \\
1. No tax subsidy & 86.9 & 74.7 & 89.2 & 62.4 & 22.7 & 10.8 \\
Tax subsidy only to a certain group: & & & & & & \\
2. $(\mathrm{x}=1$ and age $\leq 55)$ or $(\mathrm{x}=2$ and age $\leq 43)$ & 88.9 & 75.3 & 91.4 & 20.8 & 7.7 & 9.1 \\
3. $\mathrm{x}=1$ and age-adj CR & 88.9 & 75.5 & 91.3 & 18.1 & 7.5 & 9.1 \\
4. x=1, income $<2 *$ FPL and age-adj CR & 89.5 & 76.3 & 91.8 & 17.3 & 7.3 & 8.5 \\
\hline
\end{tabular}

\begin{tabular}{|l|c|c|c|c|c|c|}
\hline & \multicolumn{3}{|c|}{ Employment (\%) } & \multicolumn{3}{|c|}{ Insurance (\%) } \\
& All & LE & HE & Unins & Indiv & MCD \\
\hline After-ACA baseline & 89.1 & 79.8 & 90.8 & 8.9 & 18.5 & 10.1 \\
1. No tax subsidy & 88.3 & 79.9 & 89.8 & 31.1 & 24.2 & 10.4 \\
Tax subsidy only to a certain group: & & & & & & \\
2. $\quad \mathrm{x}=1$ and age $\leq 55)$ or $(\mathrm{x}=2$ and age $\leq 43)$ & 88.6 & 79.8 & 90.1 & 9.6 & 18.8 & 10.3 \\
3. $\mathrm{x}=1$ and age-adj CR & 88.3 & 79.8 & 89.8 & 8.8 & 19.5 & 10.1 \\
4. $\mathrm{x}=1$, income $<2^{*}$ FPL and age-adj CR & 88.6 & 80.1 & 90.0 & 8.6 & 19.2 & 10.1 \\
\hline
\end{tabular}

Table 10: The effect of tax subsidy reform after the ACA

\section{B Changes introduced by the ACA}

This section describes how the ACA provisions change the baseline model.

\section{B.1 Household problem}

After the reform, a working-age household may be subject to penalties if he stays uninsured or may receive subsidies to buy individual health insurance. Also, more households will be eligible for Medicaid. The eligibility for subsidies and the Medicaid expansion 
depends on a household's total income $\left(y_{t}^{\text {tot }}\right)$; penalties are a function of the taxable income $\left(y_{t}\right)$. We can rewrite the budget constraint of a working-age household (4) in the following way:

$$
\begin{gathered}
k_{t}(1+r)+\widetilde{w} z_{t}^{e, x} l_{t}+T_{t}^{S I}+B e q_{e}+\operatorname{Sub}\left(y_{t}^{t o t}, i_{H}^{\prime}\right)=\left(1+\tau_{c}\right) c_{t}+k_{t+1}+ \\
x_{t}\left(1-q\left(x_{t}, i_{t}\right)\right)+P_{t}+\operatorname{Tax}+\operatorname{Pen}\left(y_{t}, i_{H}^{\prime}\right) .
\end{gathered}
$$

Here $S u b\left(y_{t}^{\text {tot }}, i_{H}^{\prime}\right)$ and $\operatorname{Pen}\left(y_{t}, i_{H}^{\prime}\right)$ are subsidies and penalties correspondingly. A household with income above $400 \%$ of the Federal Poverty Line (FPL) cannot get subsidies. People having income below $400 \%$ of FPL and receiving an ESHI offer are eligible for premium subsidies in the individual market only if their employee's contribution $(\bar{p})$ exceeds $9.5 \%$ of their total income. The subsidy structure ensures that individuals within a certain income category do not spend more than a certain fraction of their income on health insurance. More specifically, spending on individual insurance premiums is limited to the percentage of total income shown in Table $11 .^{26}$

\begin{tabular}{|c|c|}
\hline \hline Maximum premium spending (\% of income) & Income categories (\% of FPL) \\
\hline 2.0 & $<133$ \\
3.5 & $133-150$ \\
5.2 & $150-200$ \\
7.2 & $200-250$ \\
8.8 & $250-300$ \\
9.5 & $300-400$ \\
\hline \hline
\end{tabular}

Table 11: Maximum spending on individual insurance as a percentage of total income after subsidies

The income eligibility threshold for the general Medicaid program is increased to $133 \%$ of FPL. There are no changes in the Medically Needy program.

An uninsured person whose insurance premium in the individual market is less than $8 \%$ of his income has to pay a penalty. The penalty is determined as

$$
\operatorname{Pen}\left(y_{t}, i_{H}^{\prime}\right)=\max \left\{0.025 y_{t}, \$ 695\right\} \quad \text { if } \quad i_{H}^{\prime}=U
$$

\section{B.2 Insurance sector after the reform}

The reform imposes a heavy regulation on the individual insurance market. Insurance companies can no longer condition premiums on the current medical cost of individuals.

\footnotetext{
${ }^{26}$ The subsidy function specified in the Bill is slightly more complicated: for each income category it specifies the range of maximum premium spending as a fraction of income. We approximate this range by selecting the midpoint of a corresponding interval. For example, the range for the income category $133-150 \%$ of FPL is $3-4 \%$ and we approximate it by the midpoint $3.5 \%$.
} 
The insurance premium of an individual of age $\widehat{t}$ will be determined by

$$
p_{I}(\hat{t})=(1+r)^{-1} \gamma \frac{\left(\int_{\mathbf{t}=\widehat{t}} \mathbf{1}_{\left\{i_{H}^{\prime}(\mathbf{s})=I\right\}} E M\left(x_{t}, t\right) \Gamma(\boldsymbol{s})\right)}{\int_{\mathbf{t}=\widehat{t}} \mathbf{1}_{\left\{i_{H}^{\prime}(\mathbf{s})=I\right\}} \Gamma(\boldsymbol{s})}+\pi .
$$

Thus, after the reform the individual market premium $p_{I}$ will be a function of age only.

\section{B.3 Government constraint}

We maintain the assumption that the government runs a balanced budget. This implies

$$
\begin{gathered}
\int\left[\operatorname{Tax}(\boldsymbol{s})+\tau_{c} c_{t}(\boldsymbol{s})\right] \Gamma(\boldsymbol{s})-G+\int_{t<R} \operatorname{Pen}\left(y_{t}, i_{H}^{\prime}\right) \Gamma(\boldsymbol{s})= \\
\int_{t \geq R}\left[s s_{e}+q_{\text {med }}\left(x_{t}\right) x_{t}-p_{\text {med }}\right] \Gamma(\boldsymbol{s})+\int T_{t}^{S I} \Gamma(\boldsymbol{s})+\int_{t<R} \mathbf{1}_{\left\{i_{H}^{\prime}=M\right\}} q\left(x_{t}, 1\right) x_{t} \Gamma(\boldsymbol{s}) \\
+\int_{t<R} S u b\left(y_{t}^{t o t}, i_{H}^{\prime}\right) \Gamma(\boldsymbol{s})
\end{gathered}
$$

The left-hand side now has an additional source of revenue - penalties from those unwilling to purchase insurance. The right-hand side has an additional expenditure - subsidies. To balance the government budget we adjust $\mathcal{T}\left(y_{t}\right)$ to make it more progressive. This is done to reflect the fact that the current administration plans to finance the reform by increasing the tax burden on people with the highest income. ${ }^{27}$ More specifically, to achieve a balanced budget in the economy with the ACA provisions in place, we adjust the parameter $a_{0}$ which controls the marginal tax rate faced by the highest income group.

\footnotetext{
${ }^{27}$ More specifically, the Bill increases hospital insurance payroll tax on people with income above $\$ 200,000$ by $0.9 \%$ and imposes a $3.8 \%$ tax on unearned income for higher-income tax-payers (Kaiser Family Foundation, 2011). Our calibration strategy assumes a standard log-normal income process commonly used in macro-literature, which cannot generate the empirical fraction of top-earners. Because of this we increase the progressivity of the general tax code to capture the main idea of financing the reform by taxing the rich more.
} 


\section{References}

[1] Aizawa, N., Fang, H., 2012. Equilibrium Labor Market Search and Health Insurance Reform. Mimeo, University of Pennsylvania.

[2] Attanasio, O., Kitao, S., Violante G., 2011. Financing Medicare: A General Equilibrium Analysis. In Shoven, J.B. (Ed.), Demography and the Economy, University of Chicago Press.

[3] Capatina, E., 2011. "Life-cycle Effects of Health Risk". Mimeo, University of New South Wales.

[4] Conesa, J. C., Krueger, D., 2006. On the Optimal Progressivity of the Income Tax Code. Journal of Monetary Economics 53(7), 1425-1450.

[5] De Nardi, M., French, E., Jones, J., 2010. Why Do the Elderly Save? Journal of Political Economy, 118(1), 39-75.

[6] Erosa, A., Fuster, L., Kambourov, G. 2011 Towards a micro-founded theory of aggregate labor supply. IMDEA Working Papers N 2011-13

[7] Floden, M., 2008. A Note on the Accuracy of Markov-chain Approximations to Highly Persistent AR(1) Processes. Economic Letters 99(3), 516-520.

[8] French, E., 2005. The Effects of Health, Wealth, and Wages on Labor Supply and Retirement Behaviour. Review of Economic Studies, 72(2), pages 395-427.

[9] Gouveia, M., Strauss, R., 1994. Effective Federal Individual Income Tax Functions: An Exploratory Empirical Analysis. National Tax Journal, 47(2), 317-339.

[10] Gruber, J., 2011. The Tax Exclusion for Employer-Sponsored Health Insurance. National Tax Journal, 64 (2), 511-530.

[11] Hai, R., 2012. The Determinants of Rising Inequality in Health Insurance and Wages: An Equilibrium Model of Workers' Compensation and Health Care Policies. Mimeo, University of Pennsylvania.

[12] Hansen, G., Hsu, M., Lee, J., 2011. Health Insurance Reform: The impact of a Medicare Buy-In. Mimeo, GRIPS.

[13] Heathcote, J., Storesletten, K., Violante, G. 2010 The Macroeconomic Implications of Rising Wage Inequality in the United States. Journal of Political Economy, vol. $118(4)$, pages $681-722$ 
[14] Huang, K., Huffman, G., 2011. A Defense of the Current US Tax Treatment of Employer-Provided Medical Insurance. Mimeo, Vanderbilt University.

[15] Hubbard, G., Skinner, J., Zeldes, S., 1994. The Importance of Precautionary Motives in Explaining Individual and Aggregate Saving. Carnegie-Rochester Conference Series on Public Policy 40(1), 59-125.

[16] Hugget, R., 1993. The Risk-free Rate in Heterogeneous-Agent Incomplete-insurance Economies. Journal of Economic Dynamics and Control 17, 953-969

[17] Imrohoroglu, A., 1989. Cost of Business Cycles with Individibilities and Liquidity Constraints. Journal of Political Econoomy, 97(6), 1364-1383.

[18] Imrohoroglu, S., Kitao, S., 2011. Social Security Reforms: Benefit Claiming, Labor Force Participation and Long-run Sustainability. American Economic Journal: Macroeconomics, forthcoming.

[19] Jeske, K., Kitao, S., 2009. U.S. Tax Policy and Health Insurance Demand: Can a Regressive Policy Improve Welfare? Journal of Monetary Economics, 56(2), 210-221.

[20] Jung, J., Tran, C., 2011. Market Inefficiency, Insurance Mandate and Welfare: U.S. Health Care Reform 2010. Mimeo, University of New South Wales.

[21] Kaiser Family Foundation, 2004. The Cost of Care for the Uninsured. What Do We Spend, Who Pays, and What Would Full Coverage Add to Medical Spending? Available at http://www.kff.org/uninsured/upload/The-Cost-of-Care-for-theUninsured-What-Do-We-Spend-Who-Pays-and-What-Would-Full-Coverage-Addto-Medical-Spending.pdf

[22] Kaiser Family Foundation, 2008. Tax Subsidies for Health Insurance: An Issue Brief. Available at http://www.kff.org/insurance/upload/7779.pdf

[23] Kaiser Family Foundation, 2009. Employer Health Benefits Survey. Available at http://ehbs.kff.org/2009.html

[24] Kaiser Family Foundation, 2010. Medicaid: A Primer. Available at www.kff.org/medicaid/upload/7334-04.pdf

[25] Kaiser Family Foundation, 2011. Summary of New Health Reform Law. Available at www.kff.org/healthreform/upload/8061.pdf

[26] Kahn, J., Kronick, R., Kreger, M., Gans, D. 2005. The Cost of Health Insurance Administration in Califarnia: estimates for insurers, physicians, and hospitals. Health Affairs 24. 
[27] Kennickel, A., 2006. Currents and undercurrents: Changes in the distribution of wealth, 1989-2004. Mimeo, Federal Reserve Board.

[28] Kim, S., 2012. The Labor Supply and Welfare Effects of Early Access to Medicare through Social Security Disability Insurance. Mimeo, Ohio State University.

[29] Kopecky, K., Koreshkova, T., 2011. The Impact of Medical and Nursing Home Expenses and Social Insurance Policies on Savings and Inequality. Mimeo, Federal Reserve Bank of Atlanta.

[30] Ozkan, S., 2011. Income Differences and Health Care Expenditures over the Life Cycle. Mimeo, Federal Reserve Board.

[31] Pashchenko, S., Porapakkarm, P., 2012. Quantitative Analysis of Health Insurance Reform: Separating Regulation from Redistribution. forthcoming, Review of Economic Dynamics.

[32] Pashchenko, S., Porapakkarm, P., 2012. Welfare Costs of Reclassification Risk in the Health INsurance Market. Mimeo, Uppsala University.

[33] Prados, M., 2012. Health And Earnings Inequality Over The Life Cycle: The Redistributive Potential Of Health Policies. Mimeo, Columbia University.

[34] Ross, D., Jarlenski, J., Artiga, S., Marks, C., 2009. A Foundation for Health Reform: Findings of a 50 State Survey of Eligibility Rules, Enrollment and Renewal Procedures, and Cost-Sharing Practices in Medicaid and CHIP for Children and Parents During 2009. Kaiser Commission on Mediaid and the Uninsured.

[35] St-Amour, P., 2012. Life Cycle Responses to Medicare. Manuscript, University of Lausanne.

[36] Storesletten, K., Telmer, C., Yaron, Y., 2004. Consumption and Risk Sharing Over the Life Cycle. Journal of Monetary Economics 51(3), 609-633.

[37] Tauchen, G., Hussey, R., 1991. Quadrature-Based Methods for Obtaining Approximate Solutions to Nonlinear Asset Pricing Models. Econometrica 59(2), 371-396.

[38] Wolff, E., 2010. Recent Trends in Household Wealth in the United States: Rising Debt and the Middle-Class Squeeze - an Update to 2007. Levy Economics Institute of Bard College Working Paper No. 589.

[39] Young, E., 2010. Solving the Incomplete Markets Model with Aggregate Uncertainty Using the Krusell-Smith Algorithm and Non-Stochastic Simulations. Journal of Economic Dynamics and Control, 34(1), 36-41. 
[40] Zhao, J. (2009). The Rise in Health Spending: The Role of Social Security and Medicare. Manuscript, University of Western Ontario. 